Prepared in cooperation with the Missouri River Recovery Program

\title{
Bend-Scale Geomorphic Classification and Assessment of the Lower Missouri River from Sioux City, lowa, to the Mississippi River for Application to Pallid Sturgeon Management
}

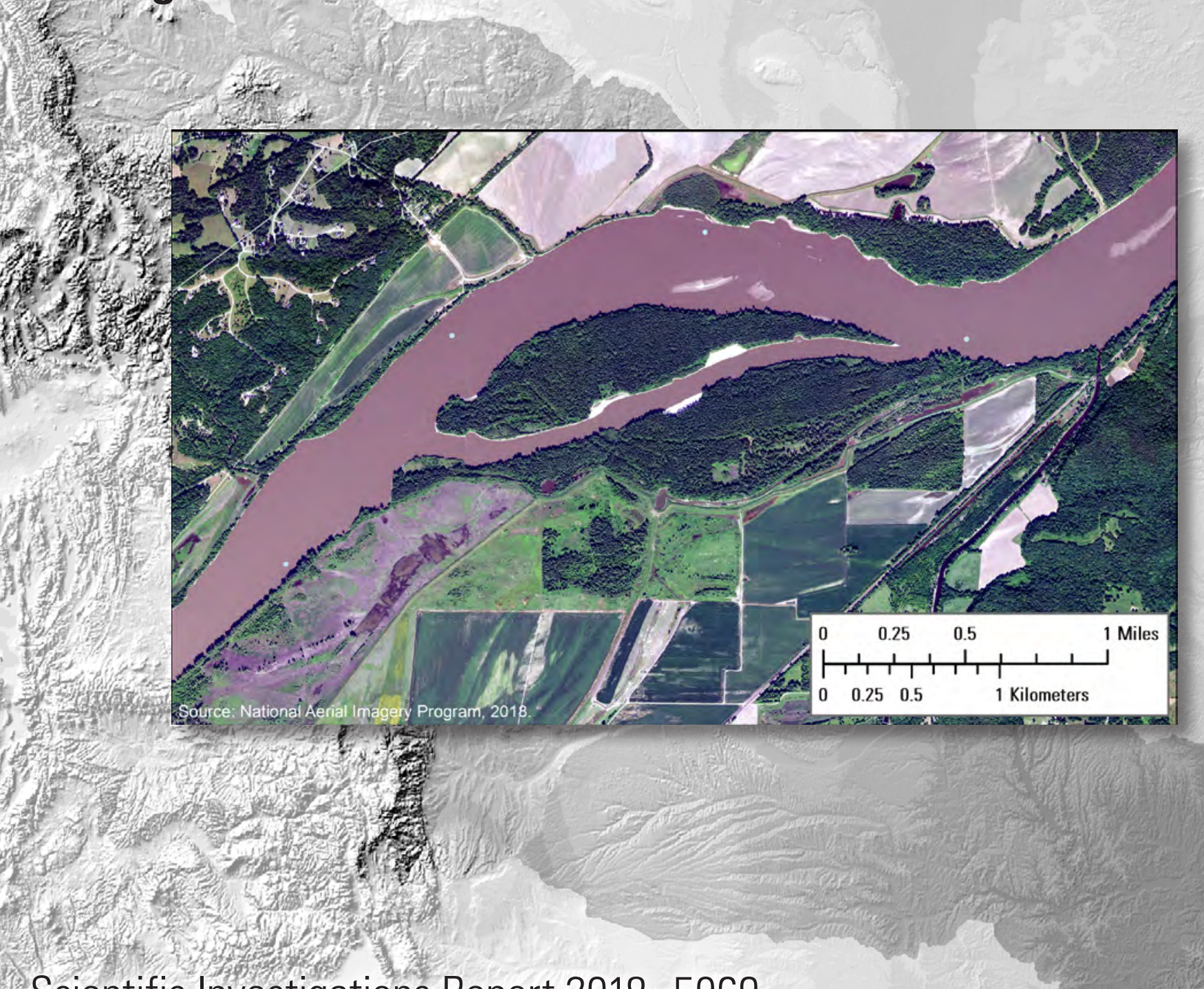

Scientific Investigations Report 2018-5069

U.S. Department of the Interior U.S. Geological Survey 
Cover. Background image: shaded relief map of the Missouri River drainage basin, U.S. Geological Survey, Earth Resources Observation and Science (EROS) Data Center. Center image: National Agriculture Imagery (NAIP), U.S. Department of Agriculture Farm Service Agency, 2018. 


\section{Bend-Scale Geomorphic Classification and Assessment of the Lower Missouri River from Sioux City, lowa, to the Mississippi River for Application to Pallid Sturgeon Management}

By Robert B. Jacobson, Michael Colvin, Edward A. Bulliner, Darcy Pickard, and Caroline M. Elliott

Prepared in cooperation with the Missouri River Recovery Program

Scientific Investigations Report 2018-5069 


\title{
U.S. Department of the Interior \\ RYAN K. ZINKE, Secretary
}

\author{
U.S. Geological Survey \\ James F. Reilly II, Director
}

U.S. Geological Survey, Reston, Virginia: 2018

For more information on the USGS - the Federal source for science about the Earth, its natural and living resources, natural hazards, and the environment-visit https://www.usgs.gov or call 1-888-ASK-USGS.

For an overview of USGS information products, including maps, imagery, and publications,

visit https://store.usgs.gov.

Any use of trade, firm, or product names is for descriptive purposes only and does not imply endorsement by the U.S. Government.

Although this information product, for the most part, is in the public domain, it also may contain copyrighted materials as noted in the text. Permission to reproduce copyrighted items must be secured from the copyright owner.

Suggested citation:

Jacobson, R.B., Colvin, M., Bulliner, E.A., Pickard, D., and Elliott, C.M., 2018, Bend-scale geomorphic classification and assessment of the Lower Missouri River from Sioux City, lowa, to the Mississippi River for application to pallid sturgeon management: U.S. Geological Survey Scientific Investigations Report 2018-5069, 35 p., https://doi.org/10.3133/sir20185069.

ISSN 2328-0328 (online) 


\section{Contents}

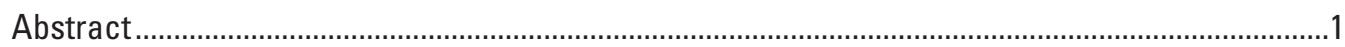

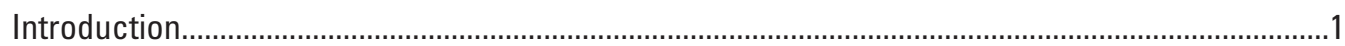

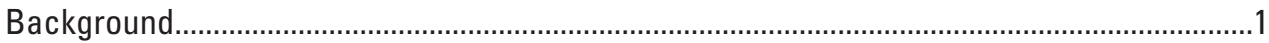

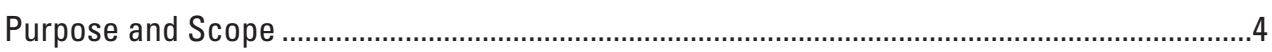

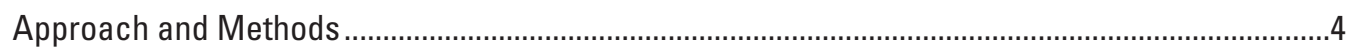

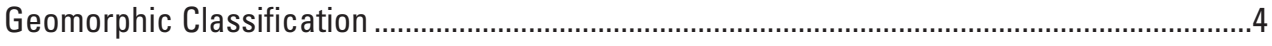

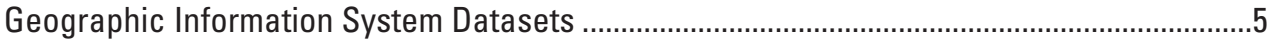

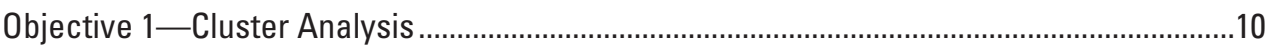

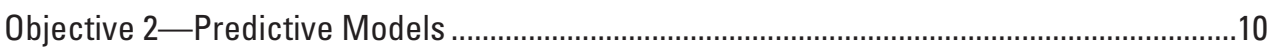

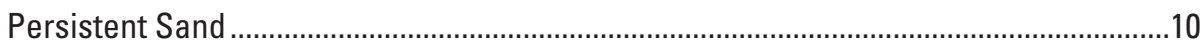

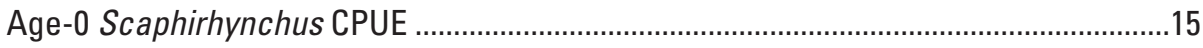

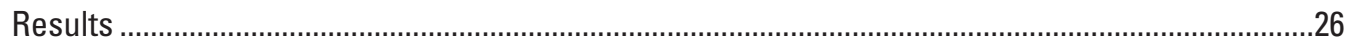

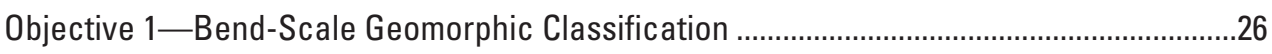

Objective 2 -Exploration of Relative Interception Capacity ..................................................28

Persistent Sand Models ...............................................................................................28

Catch Per Unit Effort Models ............................................................................................28

CPUE Model 1-CPUE with Physical Variables.........................................................30

CPUE Model 2 -CPUE with Physical Variables and Persistent Sand ......................30

Application of Bend-Scale Geomorphic Classification of the Lower Missouri River ......................30

Application of Bend Classification..................................................................................30

Application of CPUE Multiple Regression Models ............................................................

Combining Information From Bend Classification and CPUE Models.....................................32

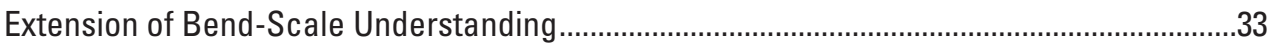

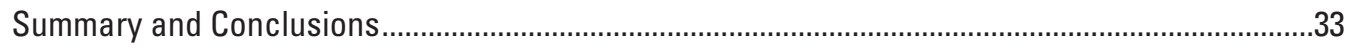

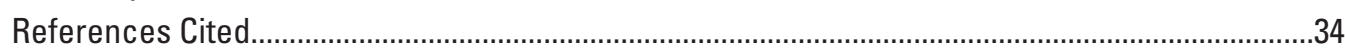

\section{Figures}

1. Map showing location of the study segments on the Lower Missouri River downstream from Sioux City, lowa, to the confluence with the Mississippi River near St. Louis, Missouri.

2. Graphs showing longitudinal distribution of selected geomorphic variables, Lower Missouri River, Gavins Point Dam, South Dakota, to confluence with the Mississippi River near St. Louis, Missouri. River flows from left to right ............................................

3. Scatterplot matrix for limited set of variables used in analysis.....................................11

4. Scree plot showing relation between within-cluster sum of squares and number of clusters for Missouri River bend classification ..............................................................12

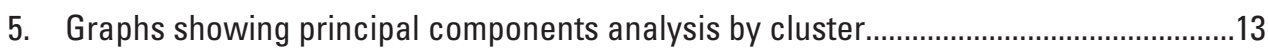

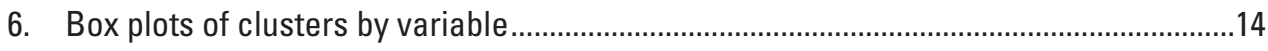

7. Map showing bends with cluster assignments, three clusters ......................................16

8. Map showing bends with cluster assignments, four clusters ..........................................17

9. Map showing bends with cluster assignments, six clusters ............................................18

10. Plot of predicted compared to measured area of persistent sand as proportion of bend area for the final model with main effects and interactions... 
11. Influence plots for main-effects variables in final persistent sand model, showing influence of individual variable while keeping other variables at mean values.....

12. Diagrams showing three-dimensional influence plots showing effects of variable interactions on predictions of proportions of persistent sand in bends

13. Influence plots for main-effects and interactive variables in final age-0 presence model, showing influence of individual variables while keeping other variables at mean values.

14. Plot of predicted compared to measured catch per unit effort for age-0 sturgeon for the final model 1 (excluding sand as a predictor variable) with main effects and interactions.

15. Influence plots for main-effects and interactive variables in final age-0 catch per unit effort model 1 (without sand), showing influence of individual variables while keeping other variables at mean values

16. Plot of predicted compared to measured catch per unit effort for age-0 sturgeon for the final model 2 (including sand as a predictor variable) with main effects and interactions

17. Influence plots for main-effects and interactive variables in final age-0 CPUE model 2 (including sand as a predictor variable), showing influence of individual variables while keeping other variables at mean values.

\section{Tables}

1. Description of datasets used in the bend-scale classification .6

2. Description of variables used in all or part of the statistical analysis................................8

3. Linear models to predict persistent sand percent area ....................................................21

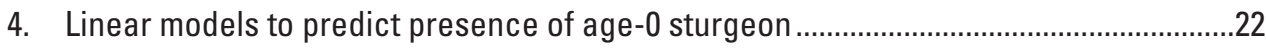

5. Cross-validation table of percent sturgeon presence and absence compared to model-predicted presence and absence, calculated by 5 -fold cross validation

6. Linear models to predict catch per unit effort of age-0 sturgeon, using scaled variables.

7. Interpretation of clusters and hierarchical relations. Clusters are arranged in roughly hierarchical order although the k-means algorithm does not guarantee a hierarchical result 


\section{Conversion Factors}

U.S. customary units to International System of Units

\begin{tabular}{|c|c|c|}
\hline Multiply & By & To obtain \\
\hline \multicolumn{3}{|c|}{ Length } \\
\hline mile (mi) & 1.609 & kilometer (km) \\
\hline
\end{tabular}

International System of Units to U.S. customary units

\begin{tabular}{lll}
\hline \multicolumn{1}{c}{ Multiply } & By & \multicolumn{1}{c}{ To obtain } \\
\hline millimeter $(\mathrm{mm})$ & Length & \\
meter $(\mathrm{m})$ & 0.03937 & inch (in.) \\
kilometer $(\mathrm{km})$ & 3.281 & foot $(\mathrm{ft})$ \\
\hline \multicolumn{2}{c}{ mile $(\mathrm{mi})$} \\
\hline square meter $\left(\mathrm{m}^{2}\right)$ & 0.6214 & \\
\hline & Area & acre \\
\hline meter per second $(\mathrm{m} / \mathrm{s})$ & 0.0002471 & foot per second $(\mathrm{ft} / \mathrm{s})$ \\
\hline
\end{tabular}

\section{Abbreviations}

AIC Akaike's Information Criterion

$\mathrm{BACl}$ before-after/control-intervention

CPUE catch per unit effort

EA 2016 Effects Analysis

GIS geographic information system

IRC interception rearing complex

PSPAP Pallid Sturgeon Population Assessment Project

USGS U.S. Geological Survey 



\title{
Bend-Scale Geomorphic Classification and Assessment of the Lower Missouri River from Sioux City, lowa, to the Mississippi River for Application to Pallid Sturgeon Management
}

\author{
By Robert B. Jacobson, ${ }^{1}$ Michael Colvin, ${ }^{2}$ Edward A. Bulliner, ${ }^{1}$ Darcy Pickard, ${ }^{3}$ and Caroline M. Elliott ${ }^{1}$
}

\section{Abstract}

Management actions intended to increase growth and survival of pallid sturgeon (Scaphirhynchus albus) age-0 larvae on the Lower Missouri River require a comprehensive understanding of the geomorphic habitat template of the river. The study described here had two objectives relating to where channel-reconfiguration projects should be located to optimize effectiveness. The first objective was to develop a bend-scale (that is, at the scale of individual bends, defined as "cross-over to cross-over") geomorphic classification of the Lower Missouri River to help in the design of monitoring and evaluation of such projects. The second objective was to explore whether geomorphic variables could provide insight into varying capacities of bends to intercept drifting larvae. The bendscale classification was based on geomorphic and engineering variables for 257 bends from Sioux City, Iowa, to the confluence with the Mississippi River near St. Louis, Missouri. We used k-means clustering to identify groupings of bends that shared the same characteristics. Separate 3-, 4-, and 6-cluster classifications were developed and mapped. The three classifications are nested in a hierarchical structure. We also explored capacities of bends to intercept larvae through evaluation of linear models that predicted persistent sand area or catch per unit effort (CPUE) of age-0 sturgeon as a function of the same geomorphic variables used in the classification. All highly ranked models that predict persistent sand area contained mean channel width and standard deviation of channel width as significant variables. Some top-ranked models also included contributions of channel sinuosity and density of navigation structures. The sand-area prediction models have r-squared values of 0.648-0.674. In contrast, the highest-ranking CPUE models have r-squared values of $0.011-0.170$, indicating much more uncertainty for the biological response variable. Whereas the persistent sand model documents that physical processes of transport and accumulation are systematic and predictable, the poor performance of the CPUE models indicate that additional processes will need to be considered to predict biological transport and accumulation.

\section{Introduction}

Management actions to avoid jeopardy to the pallid sturgeon (Scaphirhynchus albus) on the Lower Missouri River (fig. 1) require a comprehensive understanding of how pallid sturgeon life stages relate to habitat quality and quantity, particularly how much habitat is presently available and how management actions can be distributed to optimize effectiveness. Because pallid sturgeon migrate hundreds of kilometers upstream to spawn, and newly hatched free embryos can disperse hundreds of kilometers downstream before settling into supportive habitats, an understanding of river geography is fundamental.

\section{Background}

Three specific factors of river geography relate directly to pallid sturgeon life cycles. The first factor is the location of spawning habitats that will attract and aggregate reproductive adults and provide hydraulic habitats that will support fertilization, incubation, and hatching (Bemis and Kynard, 1997; Jacobson and others, 2016). Although multiple instances of spawning have been documented in the Lower Missouri River, the 2016 Effects Analysis (EA; Jacobson and others, 2016) assigned a high priority to the hypothesis that selected spawning sites on revetment on the outsides of bends were not fully functional; that is, velocities, turbulence, and shear stresses at these sites have been hypothesized to be detrimental

${ }^{1}$ U.S. Geological Survey.

${ }^{2}$ Mississippi State University.

${ }^{3}$ ESSA Technologies Ltd. 


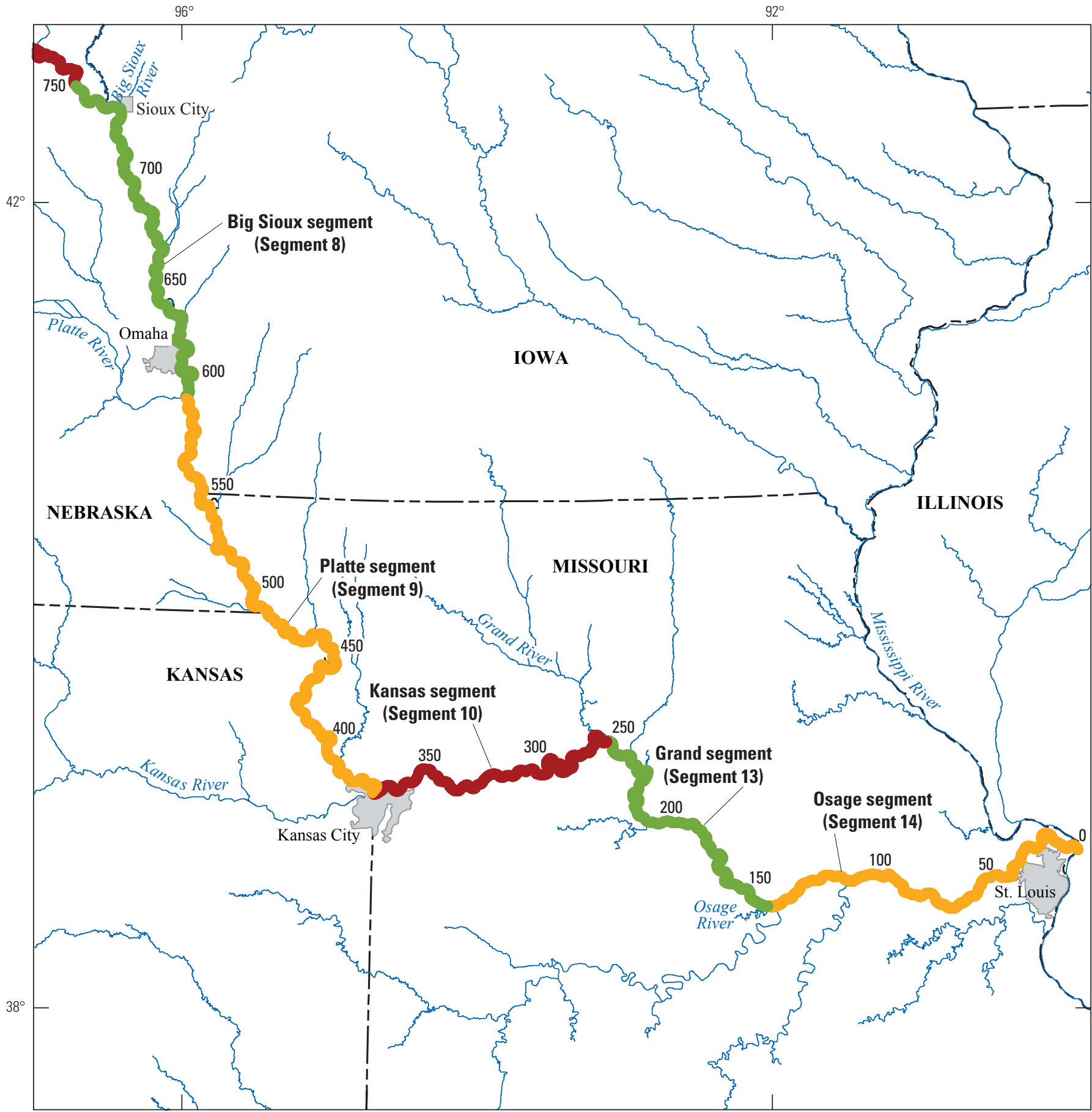

Base from U.S. Geological Survey digital data, variously dated, various scales

Universal Transverse Mercator projection, zone 15

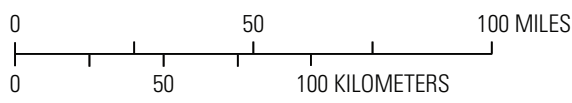

\section{EXPLANATION}

\begin{tabular}{|l|l}
\hline & Urban area \\
\cline { 1 - 1 } 150 & River mile
\end{tabular}

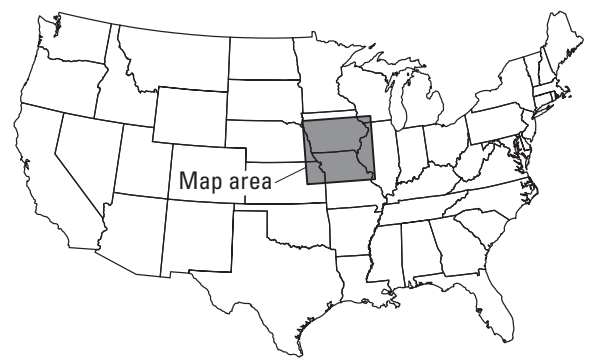

Figure 1. Location of the study segments on the Lower Missouri River downstream from Sioux City, lowa, to the confluence with the Mississippi River near St. Louis, Missouri. 
to spawning and incubation, and therefore management actions to improve spawning habitats could be instrumental in recovering the population. At the system scale (hundreds of kilometers in length), spawning-habitat design considerations focus on which river segments (tens of kilometers in length) are likely to attract upstream-migrating, reproductive adults.

The second geographic factor relates to drift and dispersal of free embryos downstream from spawning sites. The EA identified drift dynamics as another high-priority science question with implications for management actions. Drift dynamics encompass downstream movements (drift or dispersal) of larval pallid sturgeon for 9-14 days as they develop from passively transported free embryos to exogenously feeding larvae that can hold themselves in current and feed. Although research is continuing about the biological capability (development of air bladder and fins) and physical context (velocities, shear stresses, and bedforms) of settling, the high velocities of the Lower Missouri River indicate that free embryos will be advected hundreds of kilometers downstream from spawning sites (Fischenich and others, 2014). The state of practice for calculating downstream transport is to use 1-dimensional hydraulic models with advection/dispersion capabilities. The advection component of these models calculates the downstream transport of the center of mass of a population of passively drifting particles and the dispersion component calculates how hydraulic forces will increasingly spread the particles along the river as they move downstream. Based on advection/dispersion models and 82 years of hydrologic record, free embryos that are spawned upstream from the Platte River are likely to be at settling stage in the downstream-most 500 kilometers $(\mathrm{km})$ of the Missouri River or in the Middle Mississippi River (Fischenich and others, 2014; Jacobson and others, 2016).

The third geographic factor is at the scale of bends and engineering structures located within bends. The EA prioritized the hypothesis that free embryos are unable to exit the highly engineered navigation channel of the Lower Missouri River when they have used up their endogenous food resources (yolk sac) and need to begin first feeding; this transition is often referred to as "settling." The management action to mitigate starvation of larvae, based on the EA hypothesis, is to reconfigure channel morphology to allow for interception of free embryos and provision of supportive habitats for first feeding. This concept was formalized as interception-rearing complexes (IRCs) in the EA integrative report (Jacobson and others, 2016). At the bend scale, geomorphic and hydraulic factors influence the probability that a specific bend or configuration of hydraulic structures within a bend will be more

\footnotetext{
'We use "system" to describe the main stem of the Lower Missouri River from its origin at the confluence with the Mississippi River near St. Louis, Missouri, to Gavins Point Dam, South Dakota. We use "segment" to denote lengths of river having similar flow regime and valley-scale geologic constraints on form and process (Frissell and others, 1986). Within segments, "reaches" consist of multiples of cross-over bend sequences characterized by similar channel morphology. Within reaches, "bends" are defined from cross over to cross over.
}

or less likely to intercept drifting free embryos. If interception occurs at the transition to endogenous feeding, and if bioenergetically favorable foraging habitats are available, the intercepted larvae may then be retained in the bend because they can hold their position in the available channel-marginal habitat. If interception occurs before the free embryo reaches the transition to endogenous feeding and the ability to hold itself in current, then it is likely that it will not be retained and will continue downstream drift. In concept, therefore, retention of larvae - in addition to processes that promote interception - is highly dependent on the spawning location, drift rate, and development of the larva that determines where and when it is ready to settle.

The advection/dispersion models and associated models for larval development are not sufficiently precise to predict exactly where within a river segment settling is likely to occur. Hence, additional factors need to be considered at the bendto-reach scale to quantify relative likelihood of interception. The hypothesis that IRCs are necessary for survival of age- 0 pallid sturgeon can be separated into related subhypotheses (interception, food-producing habitat, foraging habitat). Also, each biologically based hypothesis can be paired with an engineering hypothesis related to the practicality of implementing IRCs:

1. Interception. - At the stage of development when free embryos need to make the transition to first feeding, they require secondary currents that are strong enough to transport them from the thalweg to adjacent supportive habitats.

- The engineering hypothesis is that alterations to channel morphology and navigation structures can provide secondary flow structures to transport free embryos into channel-marginal habitats without putting the navigation channel at risk. Secondary flow structures may include enhanced helical flow, flow expansion, and macroturbulence.

2. Food-producing habitat.-Once intercepted, the free embryo needs to transition to the exogenously feeding larval stage, during which it will need to feed, grow, and survive to contribute to population growth. The IRC hypothesis, therefore, includes the subhypothesis that food must be present. Currently available data document that age- 0 sturgeon larvae diets are dominated by Chironomidae larvae (Sechler, 2010; Harrison, 2012), and Chironomidae are preferentially associated with stable, fine sediment in low-velocity habitats (Poulton and others, 2003).

- The engineering hypothesis is that food-producing habitats can be constructed either by enhancing interception hydraulics or by creating patches of lowvelocity, depositional habitat within the IRC, or both. If food-producing habitats are limiting and need to be enhanced in IRCs, designs may need to include topwidth widening for additional habitat space. 
3. Foraging habitat.-Foraging refers to the process of finding and ingesting food items, and foraging habitat is conceptualized as hydraulic and benthic conditions that are energetically conducive to securing food while keeping energy expenditures sufficiently low to allow for growth (Jacobson and others, 2016). Collections of age-0 sturgeon indicate selection for about $0.5-0.7$ meter per second velocity and 1-3-meter (m) depth (Ridenour and others, 2011). Hydraulic measurements and models indicate that this habitat generally occurs in a band along the channel-facing facet of sand bars on inside bends; this band occurs where flow velocity is sufficient to maintain drifting food items but not so high as to cause high-energy expenditures by feeding larvae.

- The engineering hypothesis is that the combination of secondary flow and some amount of top-width widening will enhance sand bars on inside bends, providing more area that qualifies as bioenergetically favorable foraging habitat.

Although interception is considered necessary to IRC functioning, the possibility exists that either or both of the contributing habitats (food-producing and foraging) do not limit growth and survival, or that other unrecognized factors are limiting. Nevertheless, the present focus is on interception as a dominant working hypothesis.

The hypotheses associated with IRCs are intended to be addressed in science components and monitoring under development in the Missouri River Science and Adaptive Management Plan (C. Fischenich, U.S. Army Corps of Engineers, written commun., August 2017). According to the plan, the efficacy of critical interception processes will be addressed through a staircase before-after/control-intervention (BACI) design, complemented by detailed studies to understand physical and biological processes in the IRCs. Implementation of the staircase design requires identification of control and intervention reaches that are as similar as possible to minimize variance associated with reach-scale channel morphological characteristics. Identification of reaches for the staircase design experiment would also benefit from an understanding of the inherent, physical potential of a bend to intercept free embryos if they are present. The interception potential may be useful in decisions to structure learning around two different approaches: one would evaluate enhancements to bends that already have high interception potential, whereas the other would evaluate enhancement to bends with low interception potential. Either approach may provide useful understanding to guide IRC strategies.

\section{Purpose and Scope}

The purpose of this report is to present a statistically based, bend-scale geomorphic classification of the Lower Missouri River for application in assessment, planning, and monitoring of channel restoration projects to support the endangered pallid sturgeon (Scaphirhynchus albus). The geographic scope is the main stem of the Lower Missouri River from Sioux City, Iowa, to the confluence with the Mississippi River near St. Louis, Missouri (fig. 1).

The primary objective of the classification (hereafter referred to as "objective 1") is to define classes of bends that are similar, thereby allowing selection of control (or reference) and treatment bends from populations that are geomorphically similar. The secondary objective (hereafter referred to as "objective 2") is to explore whether the same geomorphic variables are useful in quantifying inherent interception capability for drifting pallid sturgeon free embryos.

\section{Approach and Methods}

Our approach is based on developing a classification of bends of the Lower Missouri River based on shared geomorphic characteristics. We then explore relations between geomorphic variables used in the classification and capacity for particle interception.

\section{Geomorphic Classification}

The structure and type of any classification is strongly determined by its use. As Rowe (1962, p. 420) stated: "...purpose is implicit in all classifications and different purposes lead to different classifications." In most cases, classification of a natural system attempts to create logical, discrete divisions in systems that are characterized by continua or gradients. A central challenge of classification is to develop objective criteria for defining useful breaks along these continua.

Driscoll and others (1984) identified two general types of ecosystem classifications: integrated and component. An integrated classification presents a system in which the total effect of interacting factors is known or understood sufficiently to define useful classes. The widely used stream classification system proposed by Rosgen (1994) is an example of an integrated classification system; the Rosgen system is based on the premise that classes of channel morphology provide a useful integration of the various factors that influence characteristics of a river reach.

In contrast, a component classification initially presents measures of individual factors, and the user is allowed to choose the factors and levels that are appropriate for the intended use. Component classifications often proceed through statistical ordination, classification, or cluster analyses of factors associated with river reaches, thereby providing an inductive and objective classification (Kondolf and others, 2003; Elliott and Jacobson, 2006a; Jacobson and others, 2010a). Component systems evaluated through cluster analysis or regression-tree type methods are also amenable to hierarchical organization (Elliott and Jacobson, 2006a). 
For longitudinal, component classifications of rivers, there are two scales of factors that may influence the classes: characteristics of the contributing drainage-basin area (watershed) and those that are based on physical characteristics within the river corridor (including the channel and adjacent valley bottom). The classification presented here is focused on corridor-scale processes, although influential characteristics of contributing watersheds could be easily added as attributes of address points if watershed characteristics (such as factors affecting water quality) were thought to be of importance in IRC functioning.

\section{Geographic Information System Datasets}

We developed geographic information system (GIS) datasets for candidate variables that were considered to describe channel complexity at the bend scale (tables 1,2). The first step in this analysis was mapping of bends in the Lower Missouri River from Sioux City, Iowa, to the Mississippi River. Bends have been identified and mapped by the Pallid Sturgeon Population Assessment Project (PSPAP; Welker and others, 2017) to serve as the fundamental units for sampling. The bend map used for our analysis is slightly different because it was created using an objective, morphology-based method. This method identifies bends based on the inflection point between successive bend arcs. The objective method has the advantage of being reproducible and independent of user judgements, and the resulting bends are very similar with nearly a 1:1 relation to the PSPAP bends. The final bend dataset contains cross-references to the PSPAP bend numbers. There are 257 bends in the U.S. Geological Survey (USGS) dataset over 1,182 $\mathrm{km}$ of the Lower Missouri River, with a mean bend length of $4.6 \mathrm{~km}$; there are 277 bends in the equivalent river distance in the PSPAP mapping. PSPAP samples were associated by geographic location with USGS bends for analysis.

Many variables were extracted from available GIS datasets to provide metrics and populations for each bend. Variables were screened using graphical methods and physical interpretations to evaluate which variables provided useful and relatively independent information. The GIS and statistical methods followed those of Jacobson and others (2010b), Elliott and Jacobson (2014), and Elliott and Jacobson (2006b). Datasets developed for this analysis are described in table 1 and are available as a USGS data release (Jacobson, 2017).

For objective 2, it was necessary to identify dependent variables that would be indicators of interception potential. Data for age-0 Scaphirhynchus (undifferentiated pallid and shovelnose sturgeon) catch per unit effort (CPUE), averaged during $2005-13$, by river miles ${ }^{2}$ were provided by the U.S. Army Corps of Engineers PSPAP (Welker and others, 2017). The mean CPUE by river mile was spatially joined to the USGS bend database (Jacobson, 2017) to provide 257 records; in the few cases where two PSPAP bends occurred within a USGS bend, the CPUE of the two were averaged for the USGS bend. These data provide an indicator of where age- 0 fish have been captured on the Lower Missouri River, but the data need to be understood in context. First, the longitudinal distribution of CPUE is likely strongly influenced by where the parent fish spawn. Because most of the CPUE samples are shovelnose sturgeon (Scaphirhynchus platorynchus), and it is thought that shovelnose are more likely than pallid sturgeon to spawn in tributaries (Keenlyne, 1997), the distribution may be highly influenced by variable and unknown drift origin locations. Moreover, the data were collected during multiple years and reflect multiple hydroclimatic conditions that may have influenced captures.

We also used persistent sand as a surrogate dependent variable in pursuing objective 2 . Persistent sand was measured through analysis of 30 years of LandSat Thematic Mapper data (Jacobson, 2017) by summing area of sand in each bend that was present at least 5 percent of the time. The 5-percent threshold is arbitrary but, through inspection, it serves to identify sandbars upstream from Omaha, Nebraska, where navigation releases inundate sandbars for much of the year. The long time series of observations provides a sample of a wide range of discharges and documents persistence and location. The persistent sand metric accounts for the highly variable detectability of emergent sandbars from imagery, as mediated by highly variable discharge. Previous work has shown that channel morphology and training structures result in highly persistent sandbar accumulations along the Lower Missouri River (Tracy-Smith and others, 2012). As calculated, the persistent presence of sand in a bend is used primarily as an indicator of interception, but it is also a metric for habitat complexity. Note that this same persistent sand variable is used as an independent variable in the cluster analysis for objective 1 and in models to predict CPUE in objective 2.

The longitudinal distribution of bend-scale variables is shown in figure 2 . The longitudinal distribution shows trends over the entire 735-mile distance as well as variation over much smaller scales.

\footnotetext{
${ }^{2}$ We use river miles upstream from the Mississippi River confluence as the standard measure of distance and location along the river because miles are the customary units used by managers, engineers, and stakeholders.
} 


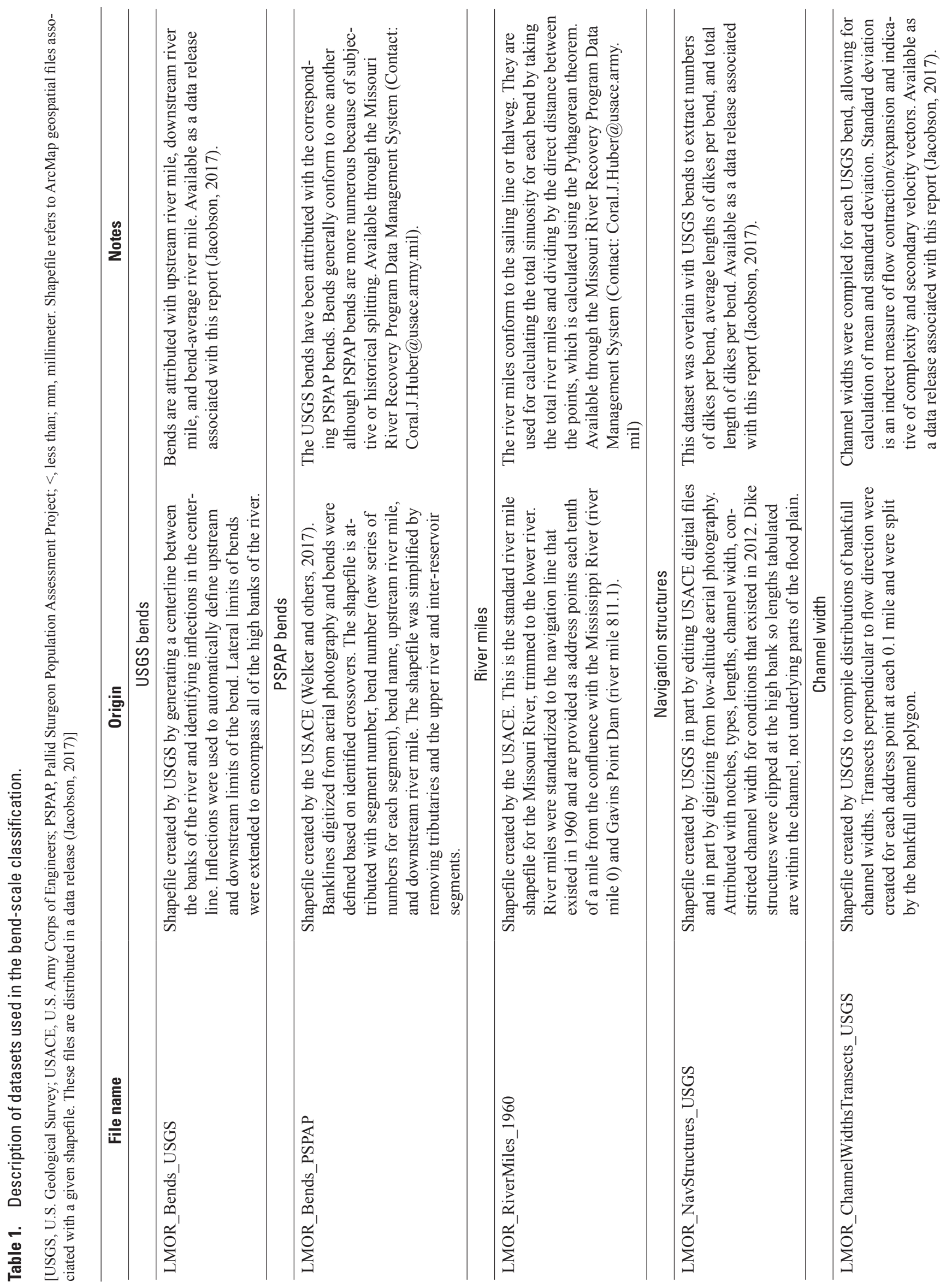




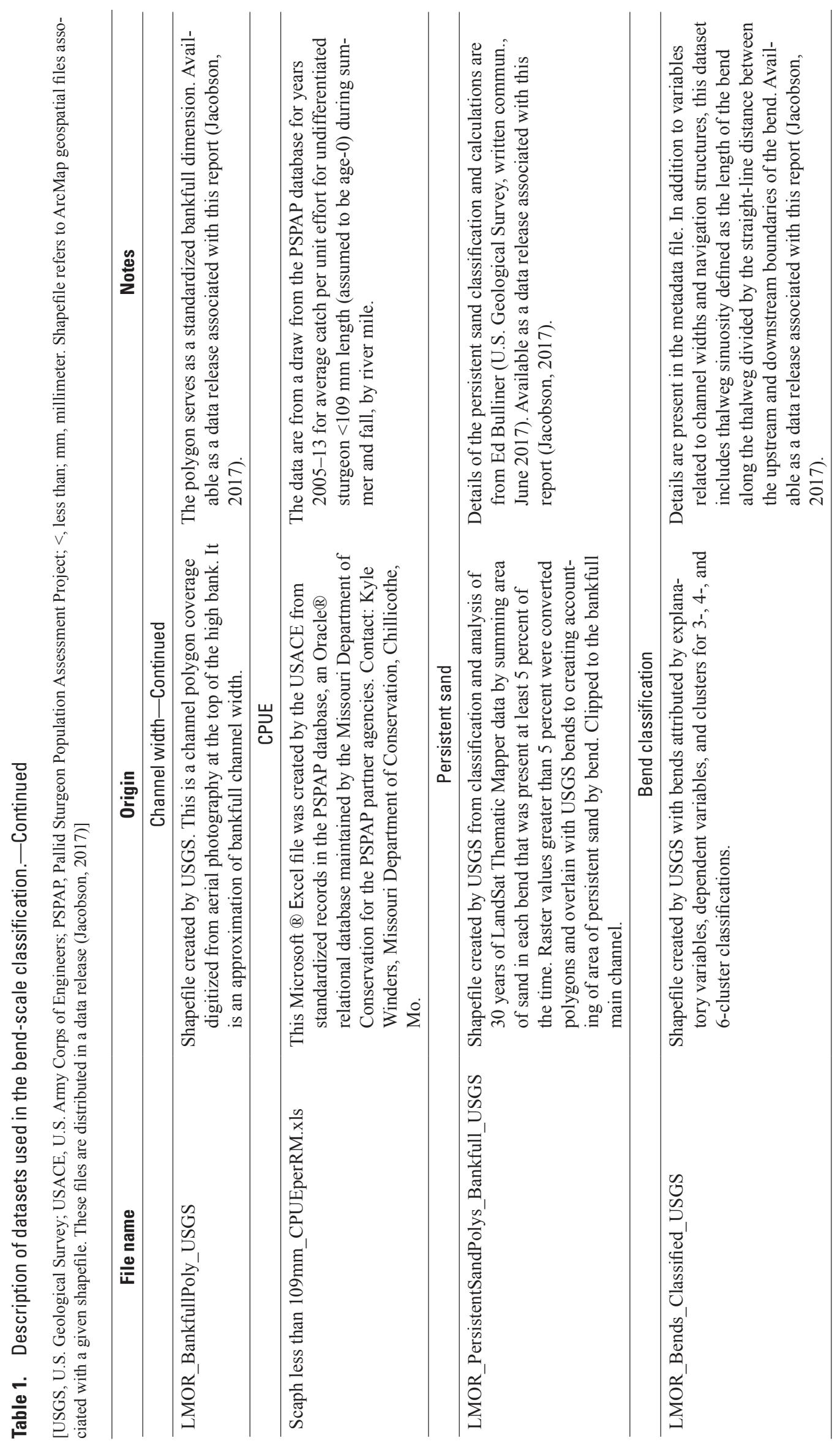




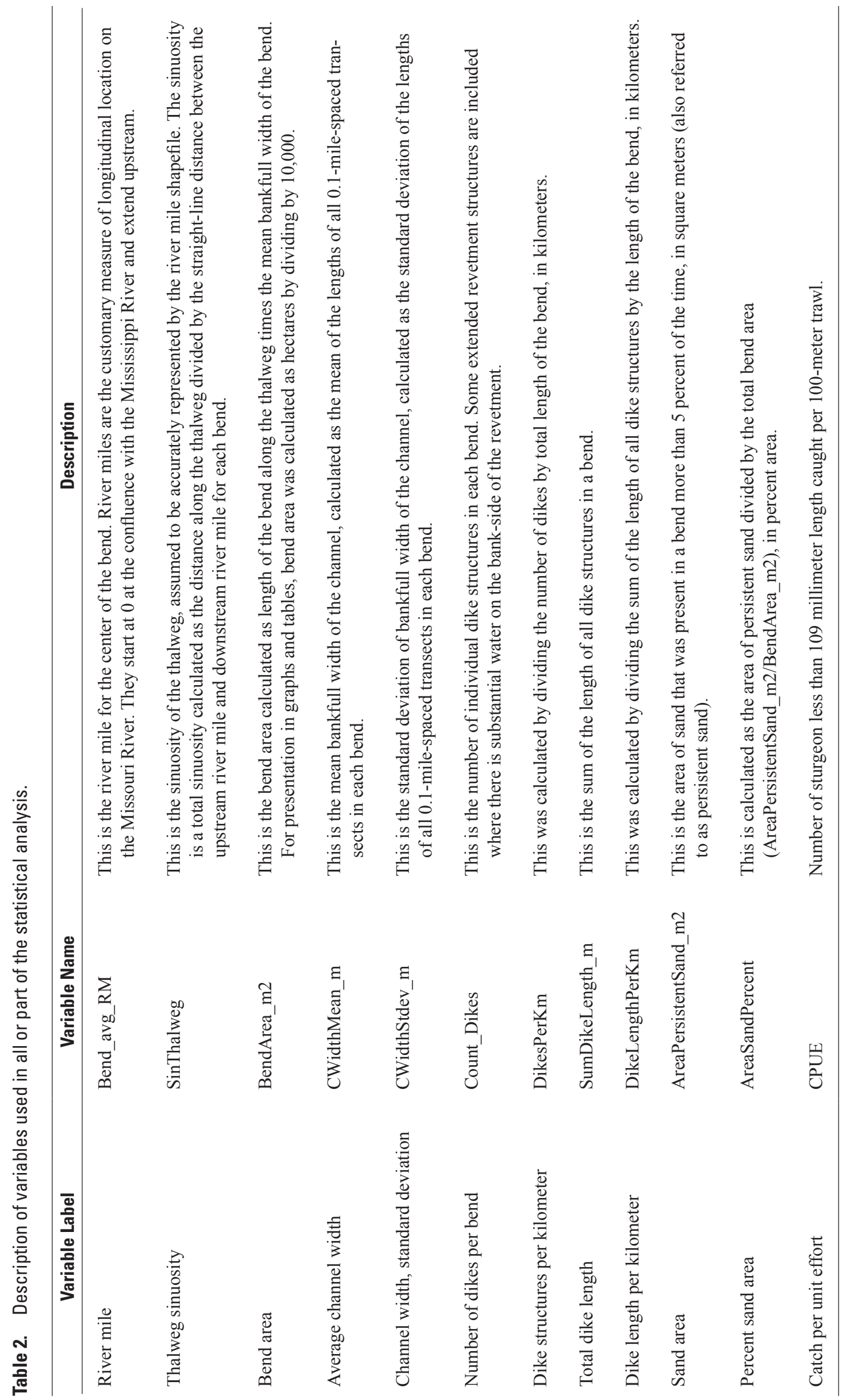



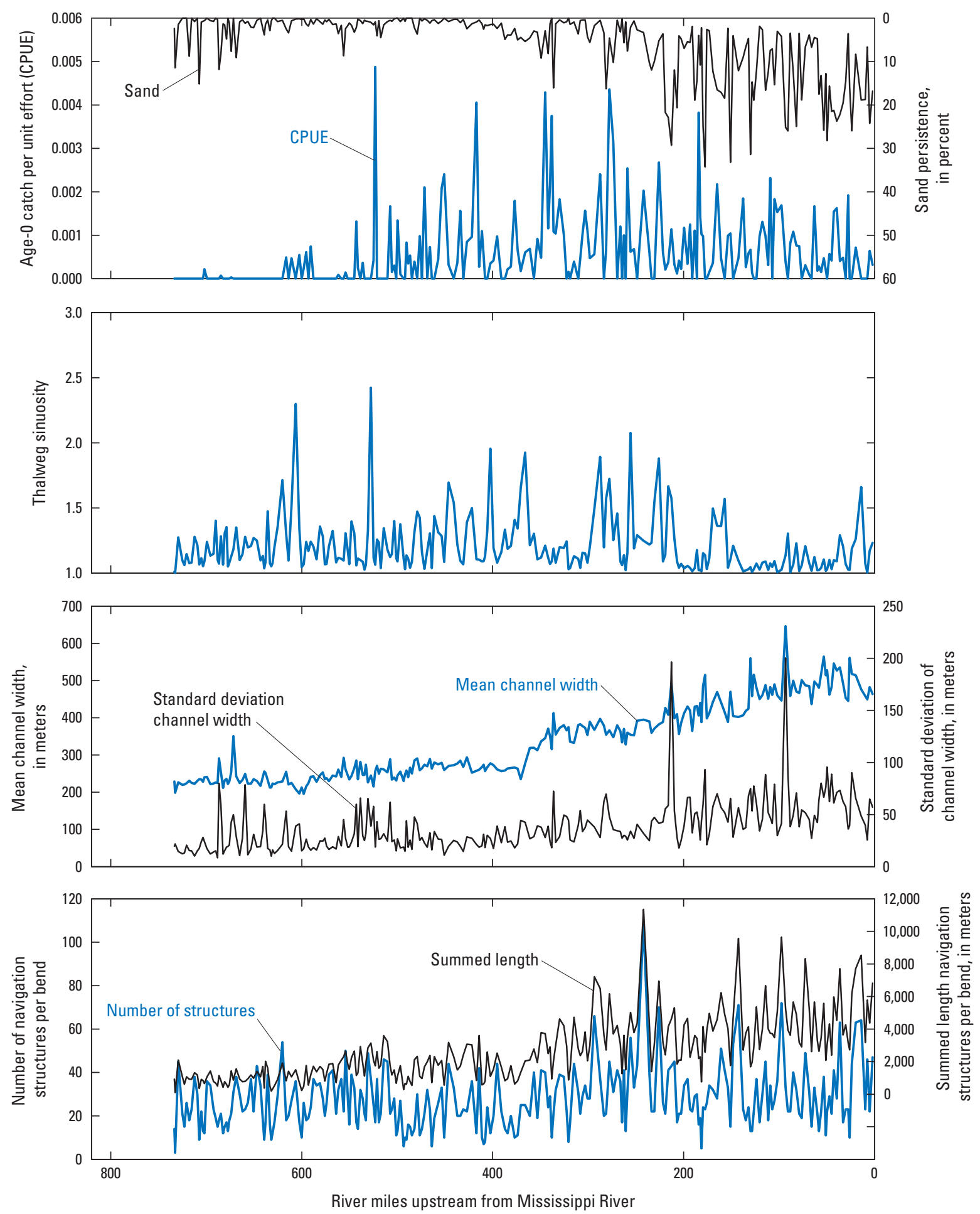

Figure 2. Longitudinal distribution of selected geomorphic variables, Lower Missouri River, Gavins Point Dam, South Dakota, to confluence with the Mississippi River near St. Louis, Missouri. River flows from left to right. 


\section{Objective 1-Cluster Analysis}

Variables used in cluster analysis for objective 1 included thalweg sinuosity, sand persistence, mean channel width, standard deviation of channel width, number of wing dikes per kilometer, and total length of wing dikes per kilometer in each bend. The graphical depiction of the data indicates substantial longitudinal variation and suggests that reaches of the river may be defined with specific combinations of characteristics. The data were analyzed to discern naturally occurring clusters using the k-means R statistical function (R Development Core Team, 2013). First, the data were scaled by dividing by the mean. Scatterplots of all variables against all variables (not shown here) were used to evaluate collinearity and normality; a subset of these (nonscaled) data is shown in figure 3. From the collinearity analysis, it was determined that number of dikes per kilometer and average lengths of dikes per kilometer were highly correlated; hence, only number of dikes per kilometer and total lengths of dikes per kilometer were retained for the analysis. Although other pairs of variables seem to be correlated, they were retained in the analysis based on a presumed high degree of physical independence. Variables were left standardized but otherwise not transformed for the cluster analysis.

Next, the optimal number of clusters was evaluated by creating a "scree" plot of within-cluster sum of squares plotted by number of clusters; this process was iterated 1,000 times to evaluate persistence in the clustering algorithm. The scree plots were used to determine the rate of decrease in sum of squares with increasing numbers of clusters (fig. 4). Decreases in slope are apparent after 3, 4, and 6 clusters with limited gains observed beyond 6 clusters. The 3-, 4-, and 6-cluster classes were retained for further analysis although useful information could also be extracted using other numbers of clusters.

The data were subsequently subjected to a k-means cluster for 3, 4, and 6 clusters using the $\mathrm{R} \mathrm{k}$-means function. The separation of clusters in multivariate space is illustrated by bivariate plots of the first two components of a principal component analysis (fig. $5 A-C$ ); this was accomplished using the clusplot function in $\mathrm{R}$. The cluster numbers were added back to the dataset and boxplots of the nonscaled values of each variable were developed to illustrate and interpret what each cluster represents (fig. 6A, $B$ ). Cluster numbers were also added back as attributes to the bend-level shapefiles to illustrate the geographic distribution of clusters (figs. 7, 8, and 9).

\section{Objective 2-Predictive Models}

Objective 2 was to explore the extent to which bends can be differentiated with respect to their present (pre-restoration) geomorphic and hydraulic capacity to intercept drifting free embryos. Our approach was to use multivariate linear models - using the same variables identified and used in the bend classification - to select the best models based on their ability to predict interception indicators. Because no direct measures of interception of age- 0 pallid sturgeon currently exist, we used two surrogate indicators (table 2):

1. Persistent sand.-Persistent sand indicates bends where hydraulic forces consistently build and maintain sandbars, which is a process that requires secondary flow components that advect sand from the thalweg to channel-marginal habitats. These are the same processes presumed to operate on drifting free embryos. Persistent sand is less affected by geographic origins of the sand and timing of interception compared to free embryos, and so sand provides an indicator that is less sensitive to annual and seasonal biological variation. The value of sand as an indicator of interception is tempered because sand is an imperfect match for physical characteristics and lacks the behaviors of developing larvae.

2. Catch per unit effort (CPUE).- - This variable was compiled as undifferentiated Scaphirhynchus (mostly shovelnose sturgeon) based on trawl catches during summer and fall, averaged over the years 2005-13, of fish less than $(<) 109$ millimeters (tables 1, 2). As indicated earlier in section Geographic Information System Datasets, CPUE should not be considered a direct measure for a variety of reasons, including the fact that most of the fish are shovelnose rather than pallid sturgeon. A large proportion of zero catches (fig. 3) characterizes the distribution of CPUE over time.

The two prospective dependent variables and some of the candidate explanatory variables are highly skewed and nonnormal (fig. 3). Both persistent sand and CPUE have modes at zero or near-zero values, thereby requiring specific approaches for these highly skewed data. The candidate predictive variables were scaled by subtracting the mean from each variable series and dividing by the standard deviation. Scaling provides some additional insight into relative influence of the variables by considering all on an equal basis; scaling also removes collinearity effects that can occur when considering models with interaction terms (Afshartous and Preston, 2011). Although centered for the multiple regression analysis, the nonscaled variables are used in diagnostic plots and to assist interpretation.

\section{Persistent Sand}

We modeled the amount of persistent sand within a bend as the proportion of the bend area that was sand at least 5 percent of the time. For modeling purposes, the persistent sand variable was transformed to a logit variable by taking the log of the sand proportion divided by 1 minus the sand proportion. We then modeled the dependent variable using candidate explanatory variables hypothesized to be physically related to sand deposition (table 3), using the glm (generalized linear model) function in R. We did an initial round of variable selection based on evaluation of obviously related variables. This 


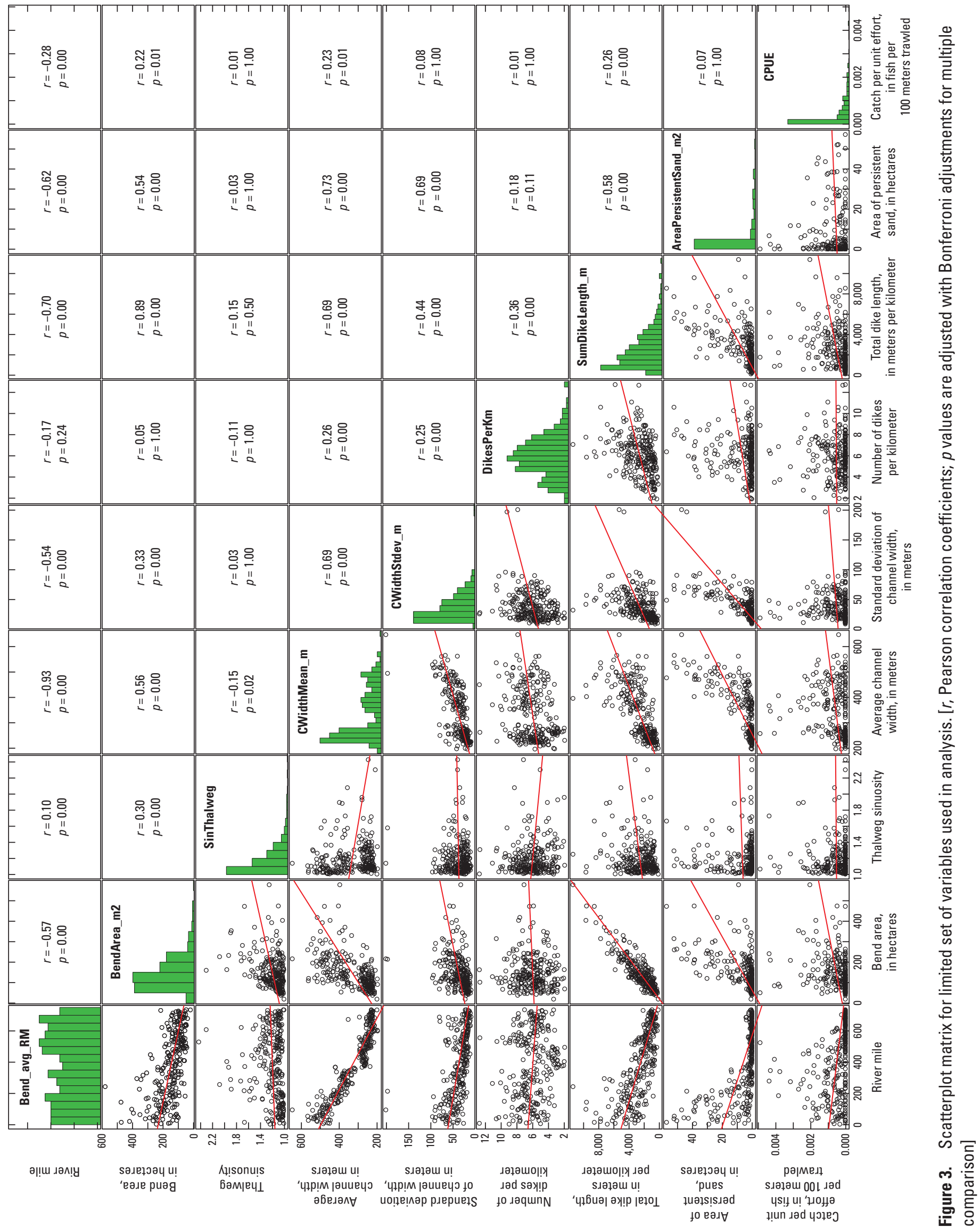


resulted in elimination of bend area (BendArea_m2), which was used to calculate the dependent variable persistent sand (AreaSandPercent), and number of dikes per bend (Count Dikes) and total dike length (SumDikeLength_m), both of which we normalized by bend length to calculate derivative variables that were maintained in the model (DikesPerKm and DikeLengthPerKm).

The initial model used all the remaining candidate variables as main effects. A second model was selected by stepping through various combinations of main-effects variables and all possible two-way interactions, using the R step function. The final model was selected based on minimizing Akaike's Information Criterion (AIC; table 3). Selection of a "best" model based on AIC accounts for information imparted by the candidate variables while penalizing for using too many variables; in this sense, the final model optimizes information content (Burnham and Anderson, 2002). The pseudo r-square values (also known as McFadden's r-square) are a measure of fit useful for relative comparisons among models for which ordinary least-squares $r$-square values are not appropriate (Hosmer and Lemeshow, 2000). Residuals were examined and no systematic biases were determined. The final model has two highly significant main-effects variables and four significant interactions (table 3). A measure of goodness of fit of the model is indicated by a plot of predicted compared to measured persistent sand (fig. 10). Plots of predicted percentpersistent-sand area aid interpretations of main effects by individual variables while setting other variables equal to their means (fig. 11). Similarly, 3-dimensional wireframe response surface plots allow for some interpretation of the complex interactions among pairs of variables (fig. 12).

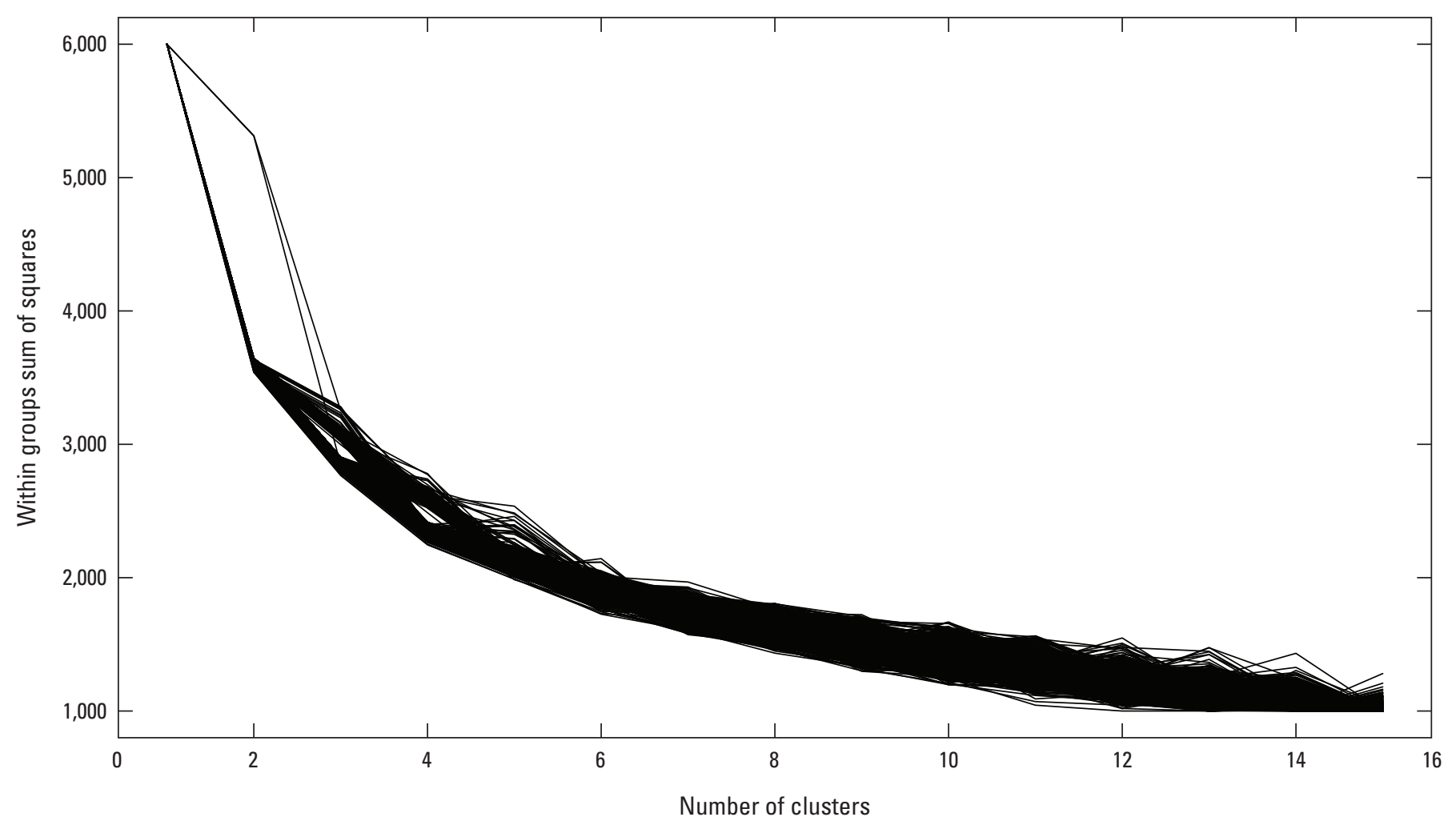

Figure 4. Scree plot showing relation between within-cluster sum of squares and number of clusters for Missouri River bend classification. 


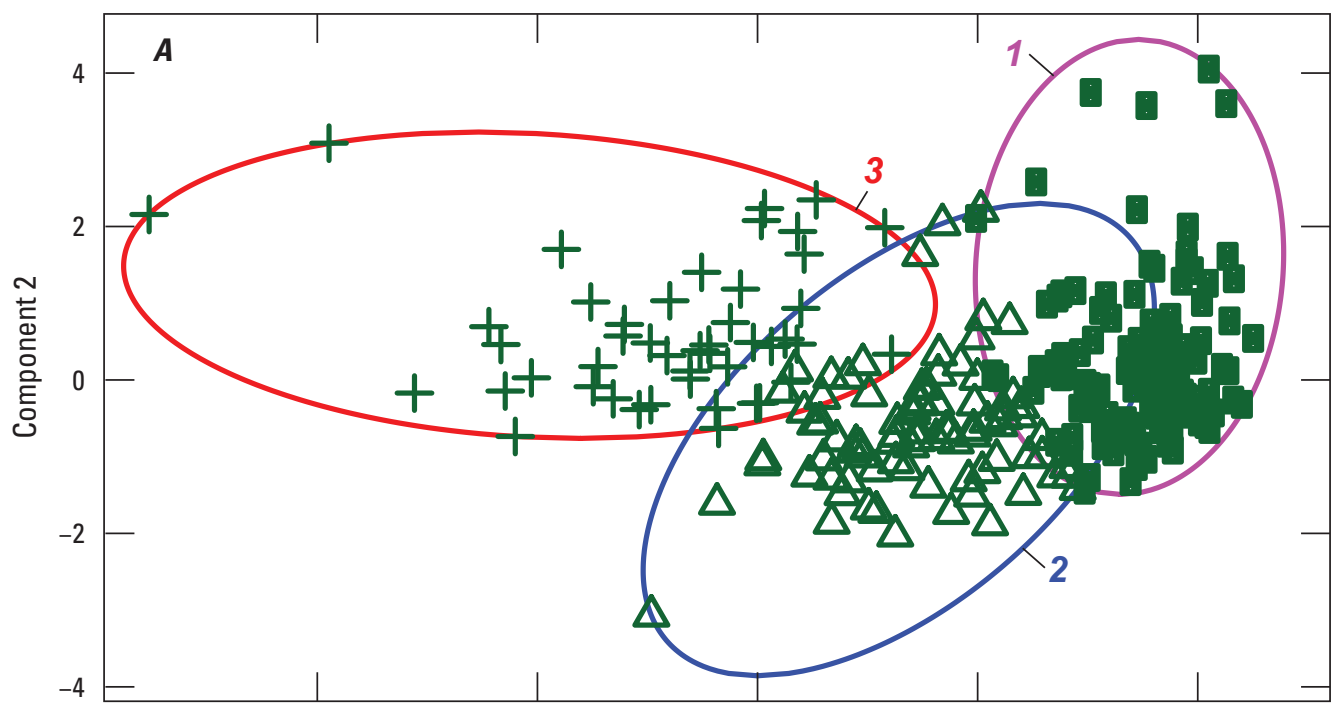

$\begin{array}{cl} & \text { EXPLANATION } \\ & \text { Cluster } 1 \\ \Delta & \text { Cluster } \mathbf{2} \\ + & \text { Cluster } 3 \\ \times & \text { Cluster } 4 \\ \nabla & \text { Cluster } 5 \\ \nabla & \text { Cluster } 6 \\ \text { Ellipses enclose the data } \\ \text { points associated } \\ \text { with each cluster }\end{array}$
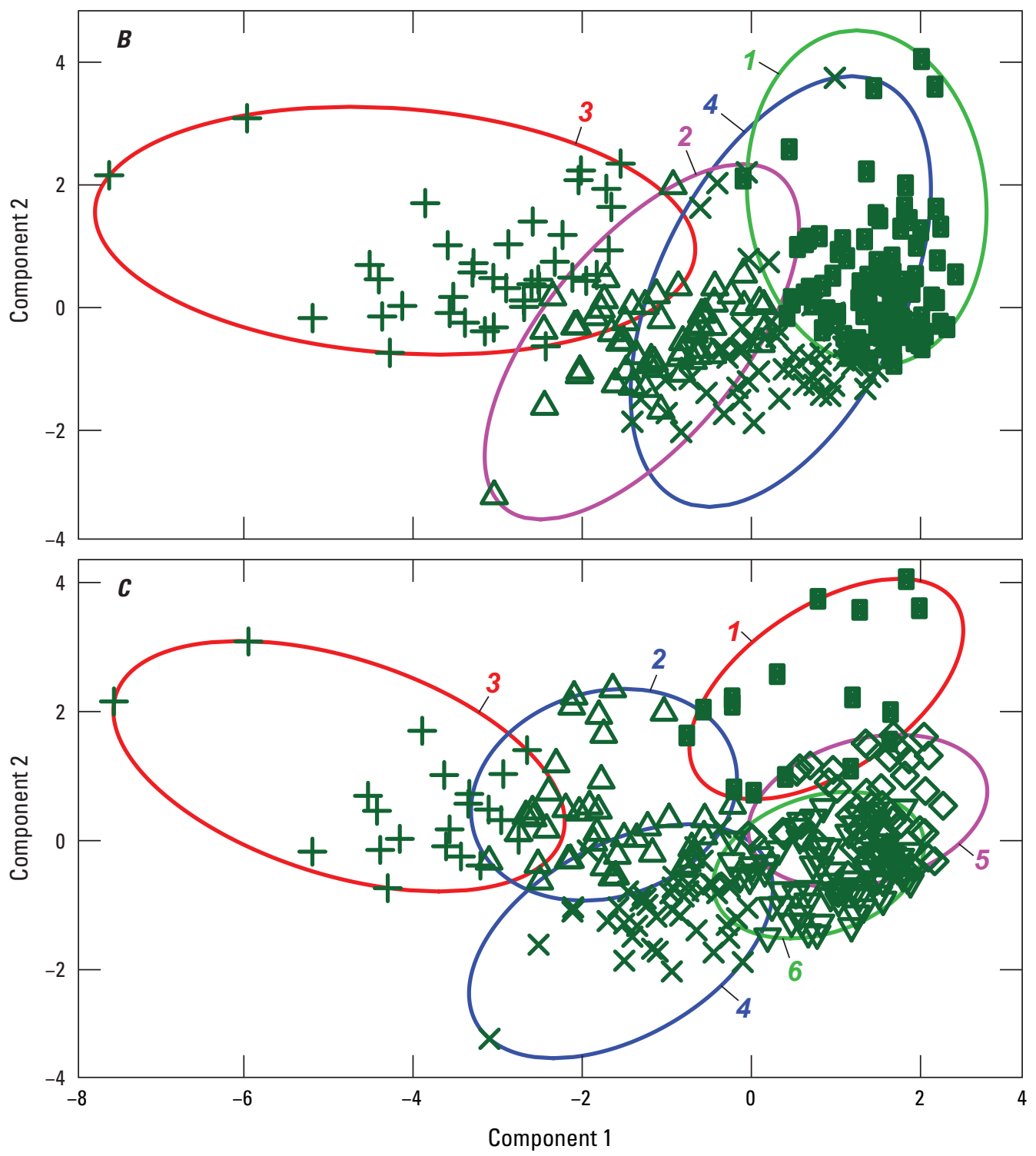

Figure 5. Principal components analysis by cluster. $A$, Three clusters. $B$, Four clusters. $C$, Six clusters. 

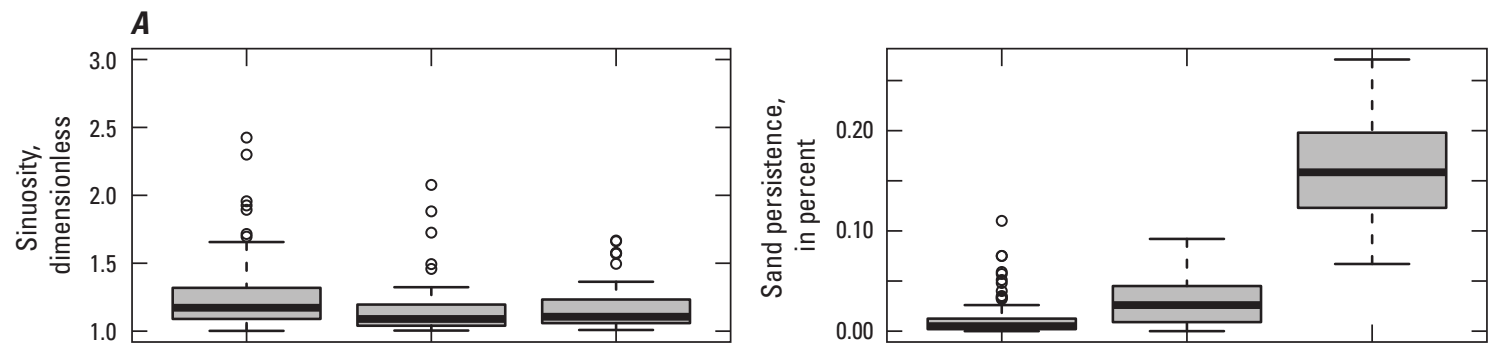

\section{EXPLANATION}

- Individual observation above 90th percentile
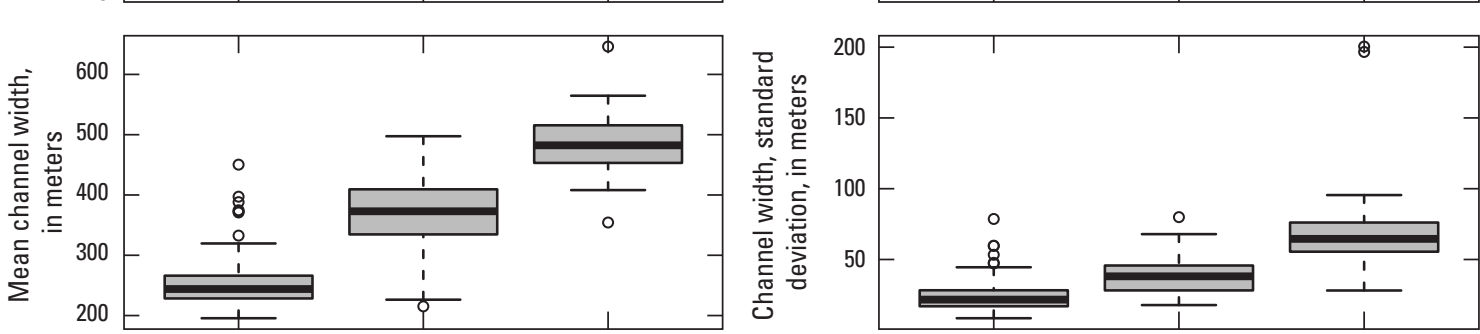

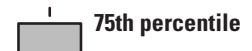 \\ 75th percentile}

50th percentil
(median)

25th percentile

1 10th percentile

- Individual observation

below 10th per-

centile
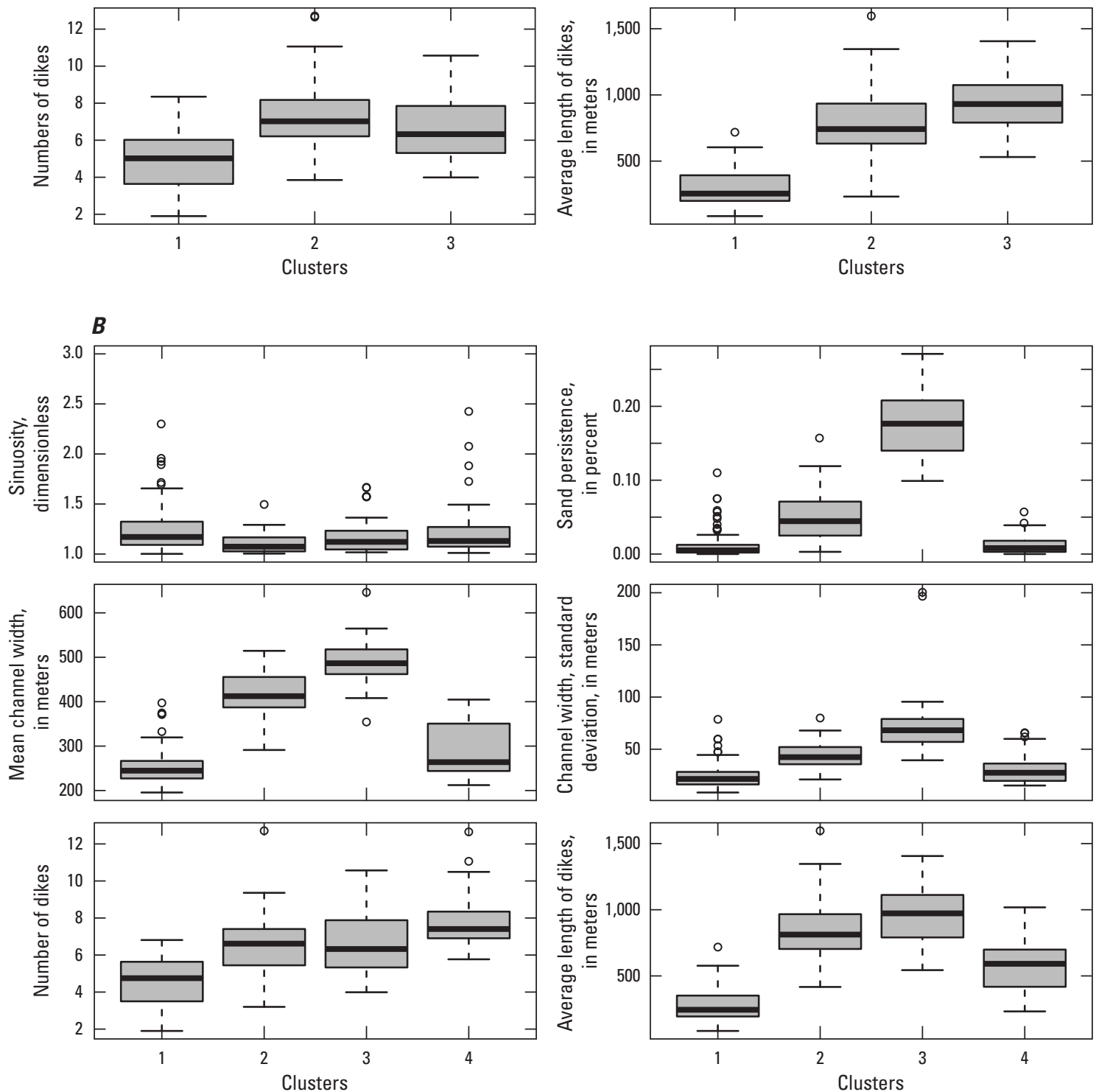

Figure 6. Box plots of clusters by variable. $A$, Three clusters. $B$, Four clusters. 

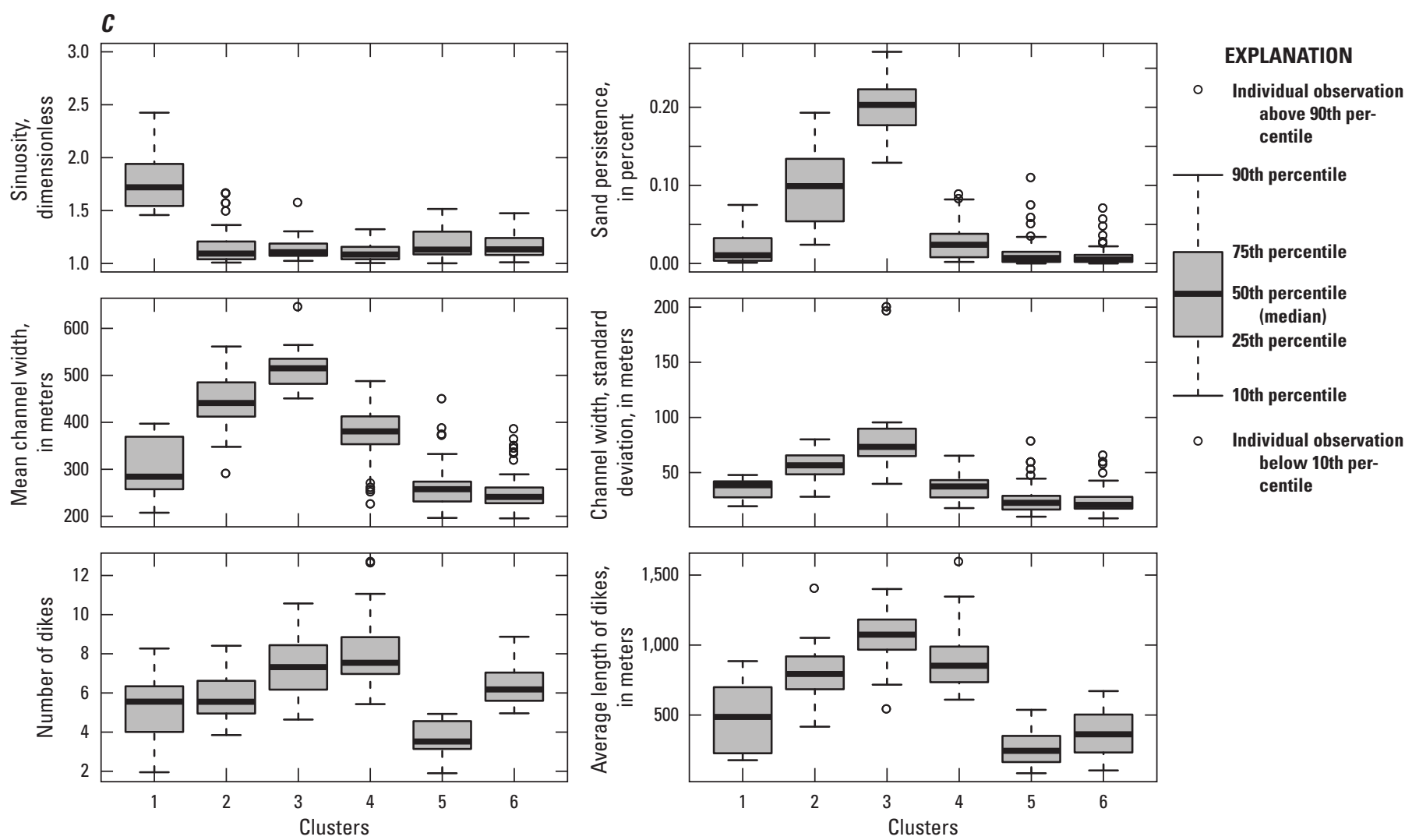

Figure 6. Box plots of clusters by variable-Continued. C, Six clusters.

As in all statistical modeling, the value of the model results depends on having relevant variables in the candidate set. In this case, we know that geomorphic characteristics at the bend scale may be only indicative of the fine-scale hydraulic processes that ultimately result in interception of free embryos. In particular, the variables related to navigation structures (number of dikes per kilometer and total length of dikes per kilometer in a bend) are unlikely to measure fully the effects of how subtle geometries of navigation structures may affect secondary currents and interception.

\section{Age-0 Scaphirhynchus CPUE}

Because the CPUE distribution is characterized by a high frequency of zero values (fig. 3), we elected to divide the modeling process into two parts. A presence/absence model was used to evaluate variables associated with zero and nonzero catches; presence/absence was modeled as a binomial response. Then, the nonzero catches were modeled separately to evaluate the relations between CPUE and candidate explanatory variables. In both cases, the $\mathrm{R}$ step function was used to identify the model with the lowest AIC using main effects and all possible 2-way interactions.

The main-effects model for presence/absence of age- 0 sturgeon and the final model with the lowest AIC are shown in table 4 . The influence of main-effects variables on presence/absence is shown in figure 13. The candidate explanatory variables were those used in the persistent sand models, with the exception that bend area (BendArea_m2) was added back into consideration because it was not used to calculate any other variables. The bends were further classified according to predicted presence probability by assigning a " 0 " to predicted probabilities less than 0.5 and a " 1 " to predicted probabilities greater than 0.5 . We assessed the presence/ absence model predictions through five-fold cross-validation, averaging actual sturgeon presence and absence as compared to predictions for each fold's test data across all folds (table 5).

The main-effects models for $\log$ (CPUE) of age- 0 sturgeon and the final model with the lowest AIC are shown in table 6. We explored two model sets. For each model set, the initial main-effects model is shown along with the final model with interactions and the lowest AIC. Candidate variables were limited to those that were selected in the final presence/ absence model. The first model set ( $\log (\mathrm{CPUE})$-model 1) used the same variables that were used in the presence/absence model (figs. 14, 15). The second model set (log(CPUE)model 2) added in persistent sand as a potential explanatory variable, recognizing that sand-bar deposits are treated as a dependent variable when considering sand transport processes but could be considered an independent variable influencing or indicating interception and (or) retention of age-0 sturgeon (figs. 16, 17). 


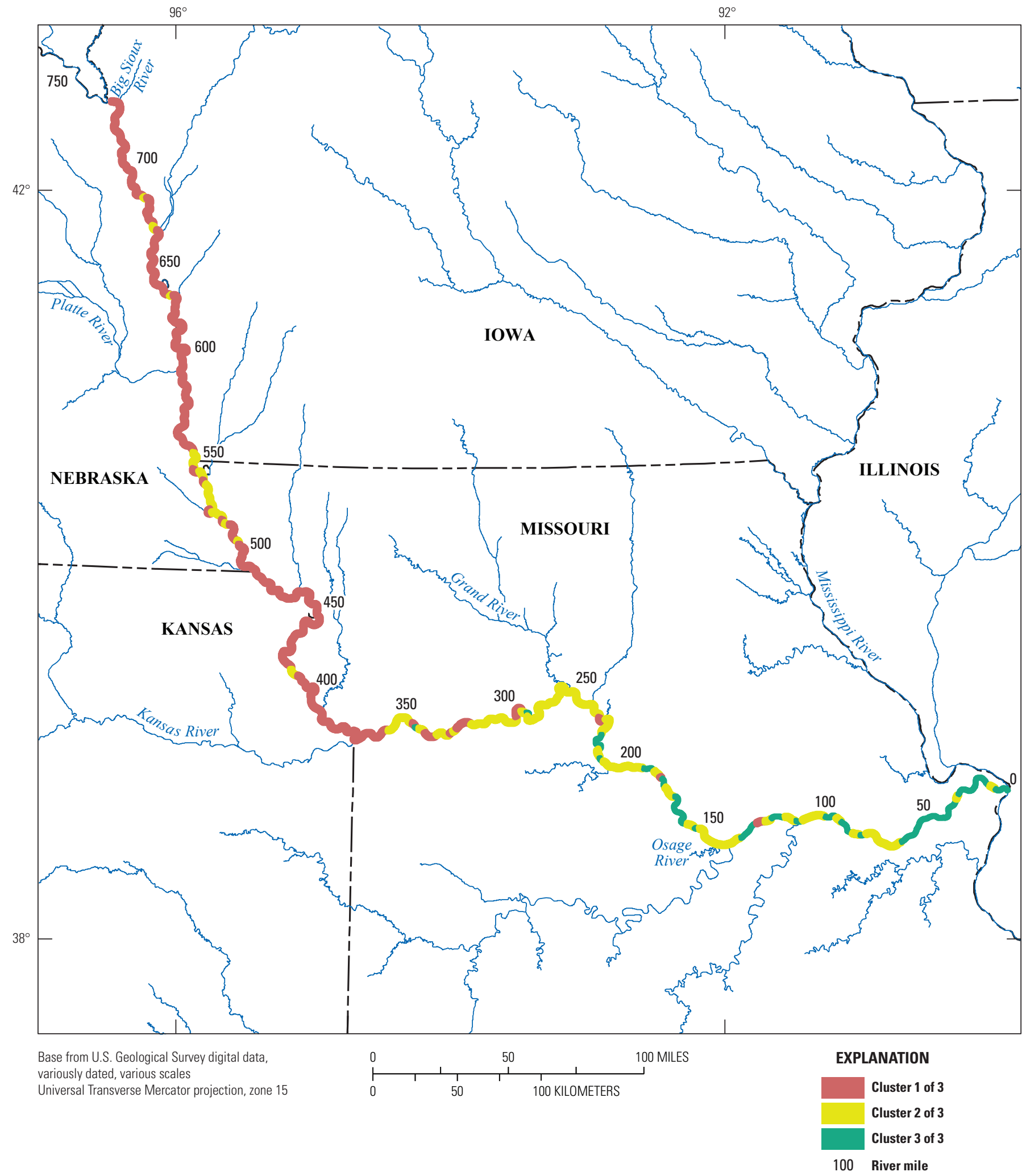

Figure 7. Bends with cluster assignments, three clusters. 


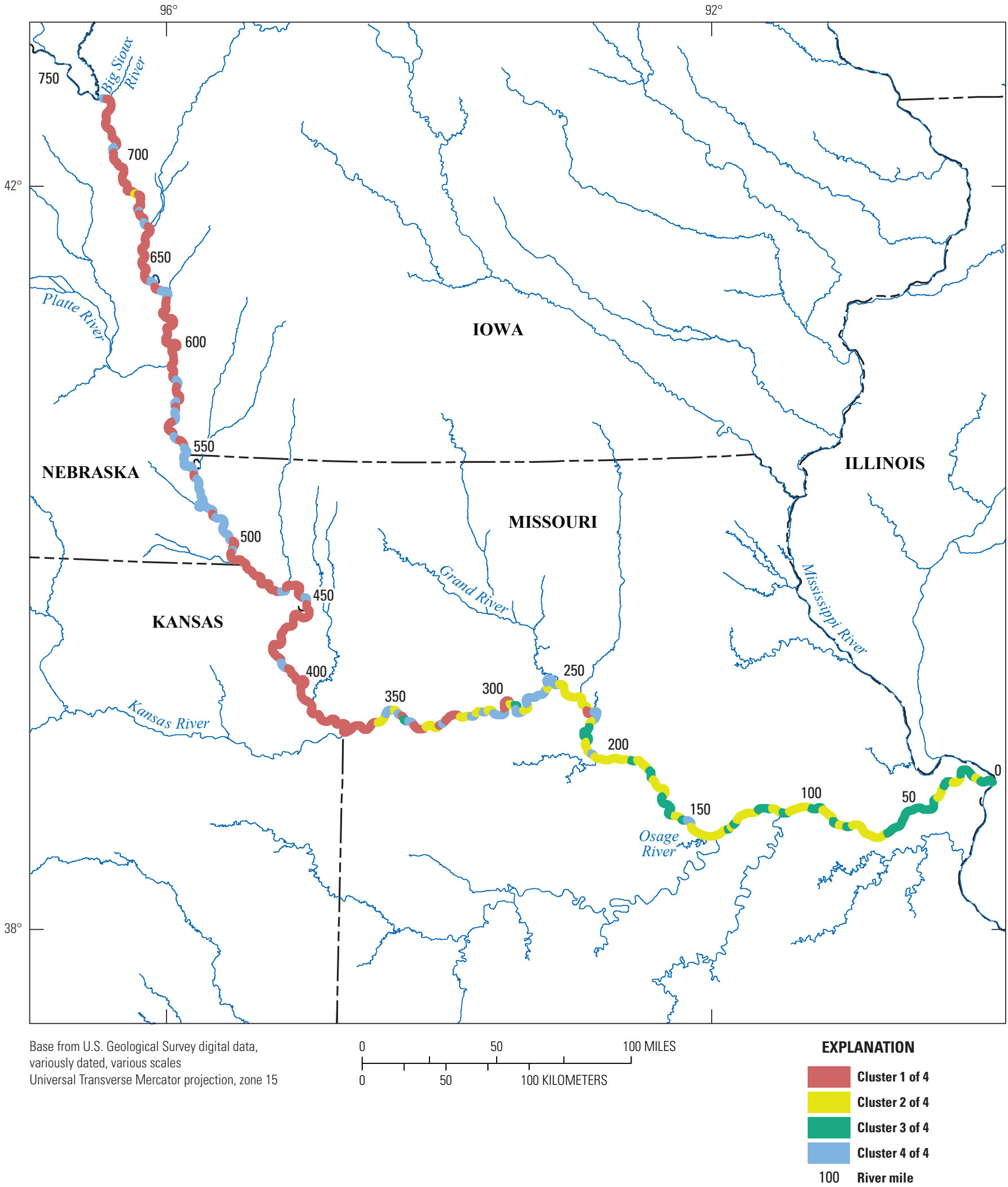

Figure 8. Bends with cluster assignments, four clusters. 


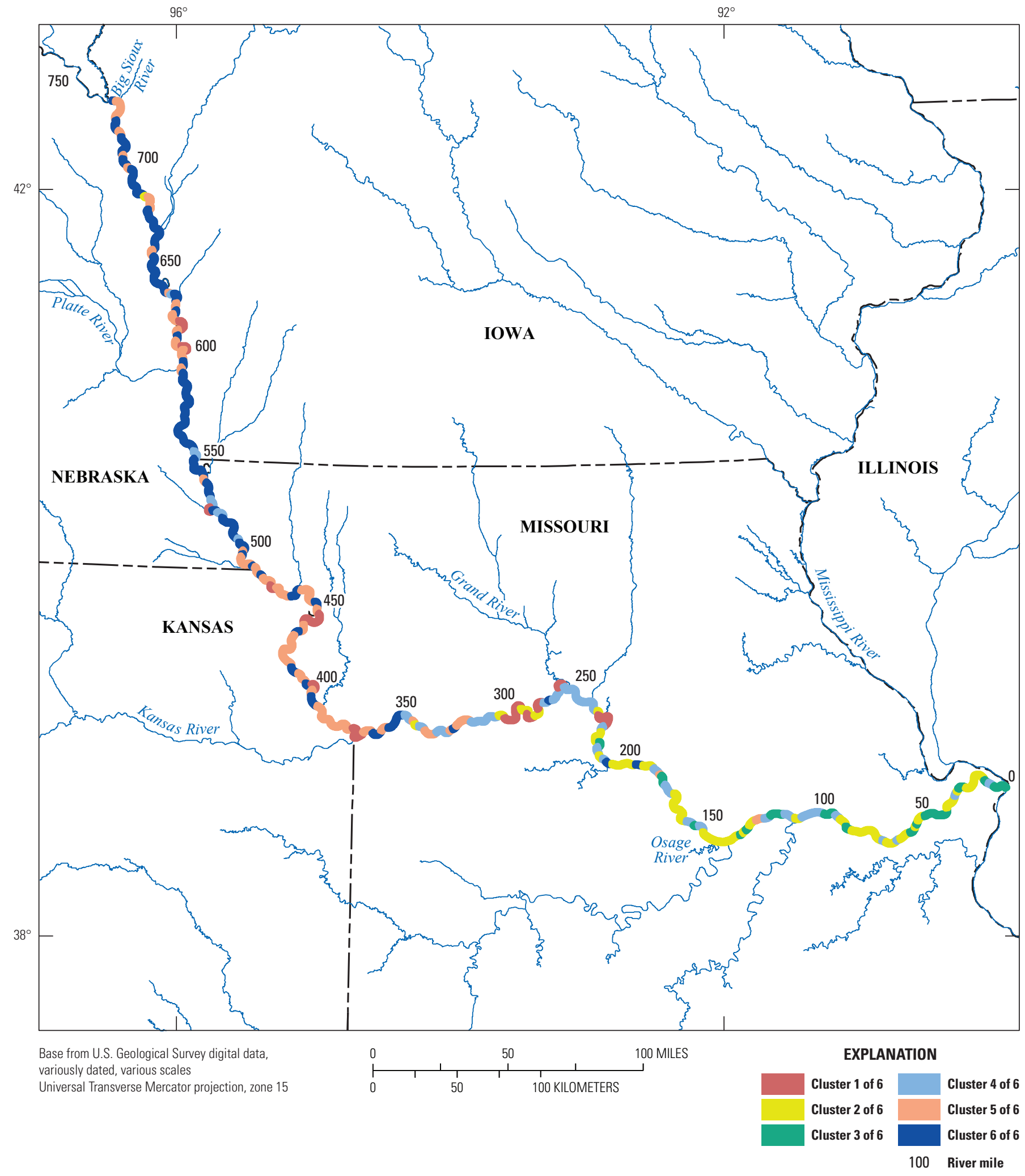

Figure 9. Bends with cluster assignments, six clusters. 


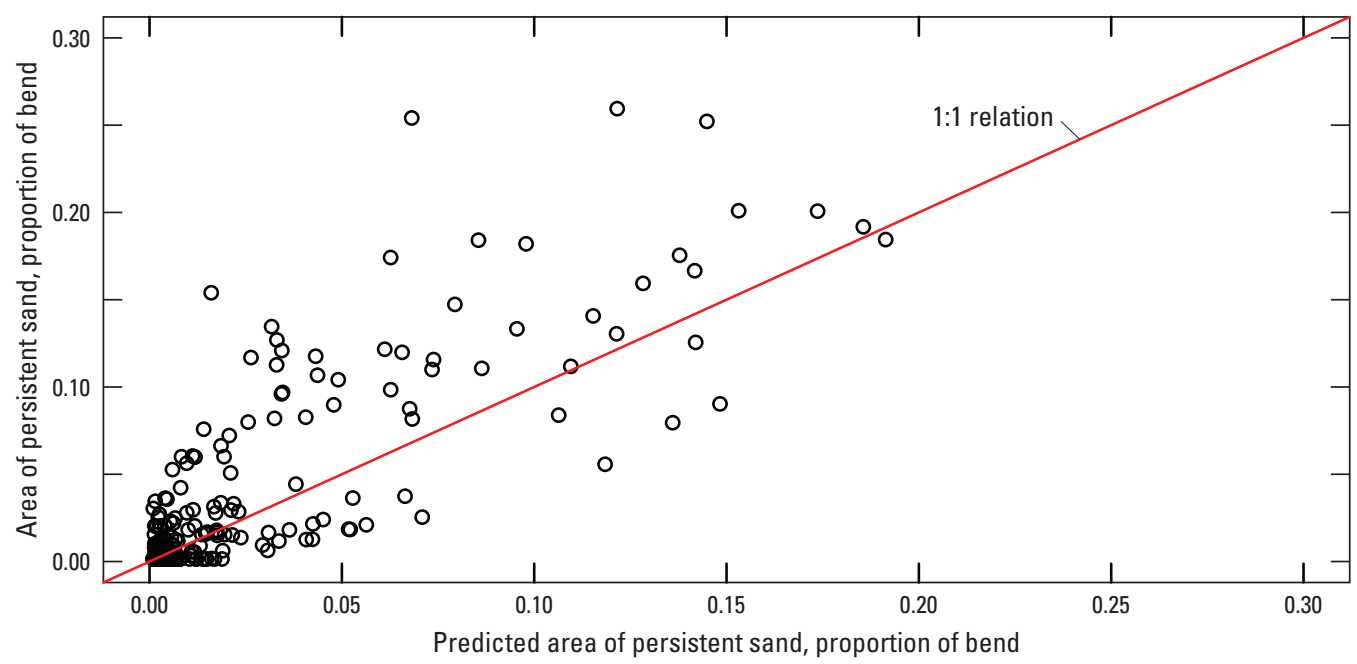

Figure 10. Plot of predicted compared to measured area of persistent sand as proportion of bend area for the final model with main effects and interactions.

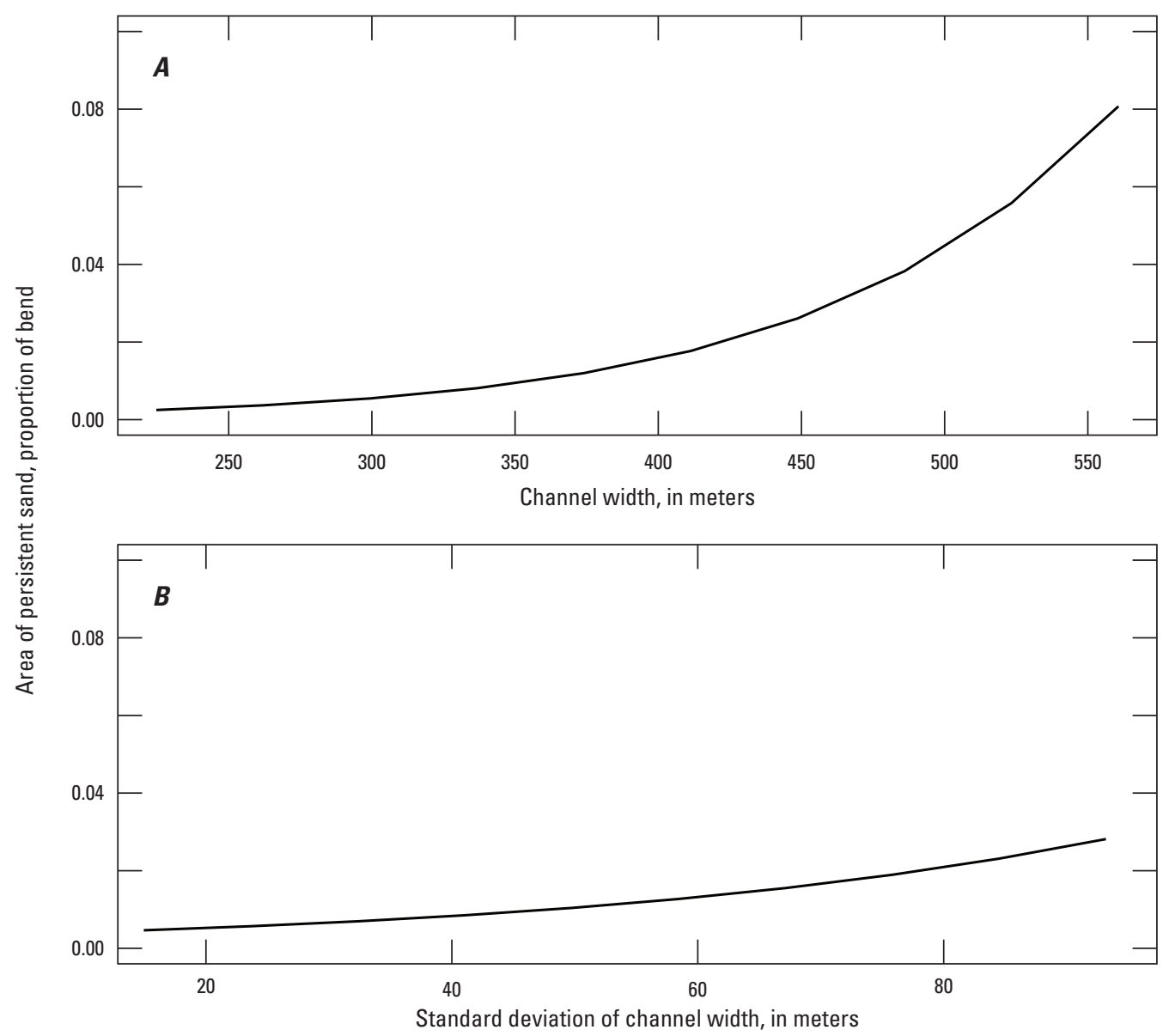

Figure 11. Influence plots for main-effects variables in final persistent sand model, showing influence of individual variable while keeping other variables at mean values. $A$, Variation of persistent sand with mean channel width. $B$, Variation of persistent sand with standard deviation of channel width. 

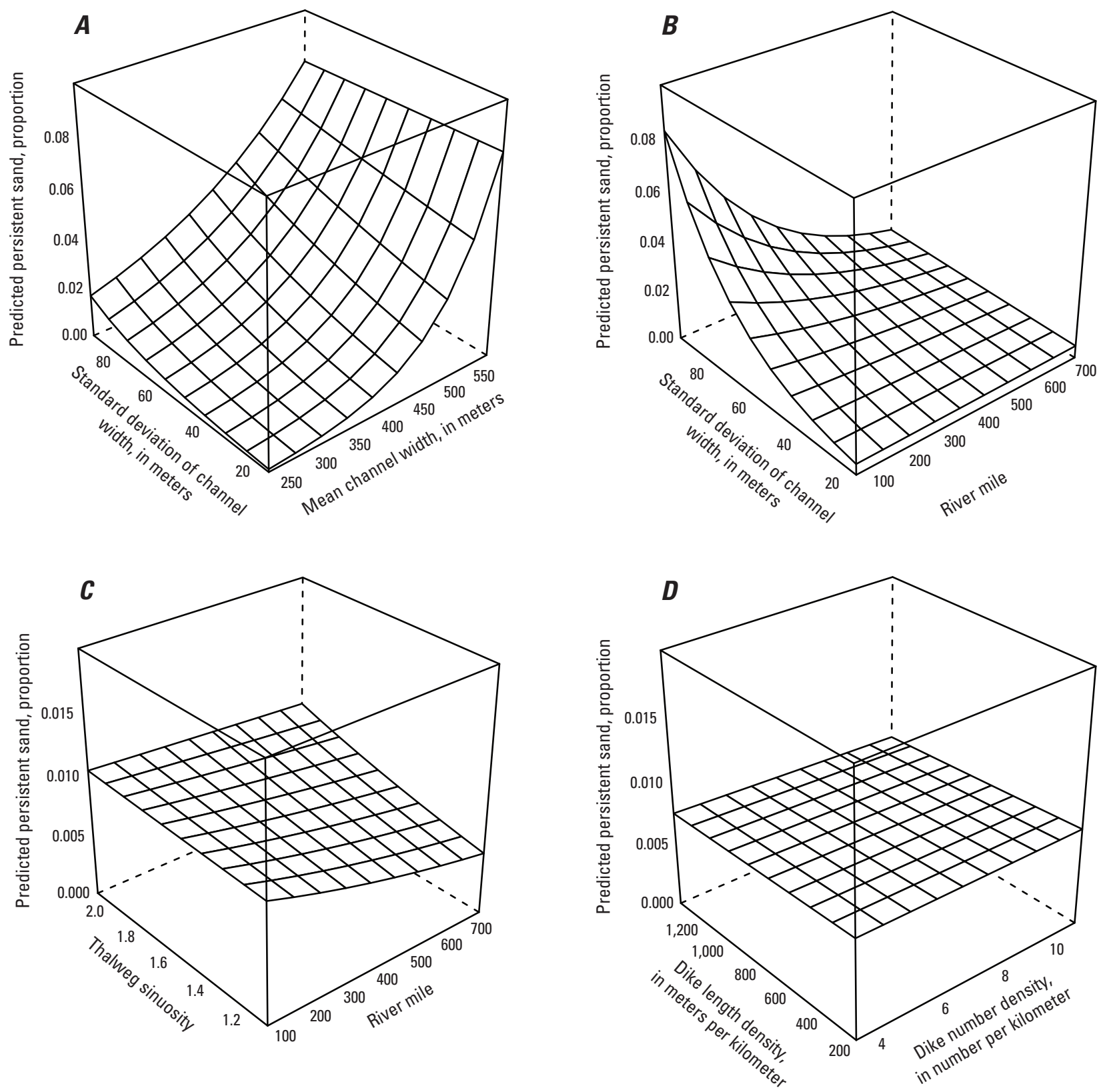

Figure 12. Three-dimensional influence plots showing effects of variable interactions on predictions of proportions of persistent sand in bends. $A$, Standard deviation of channel width and mean channel width. $B$, Standard deviation of channel width and river mile. $C$, Thalweg sinuosity and river mile. $D$, Dike length density and dike number density. 
Table 3. Linear models to predict persistent sand percent area. The models were run with scaled independent variables and logistically transformed dependent variable (Sand).

[AICc, Akaike information criterion, corrected for small sample size; --, not applicable; e, E, exponentiation; “.”' indicates an interaction between variables. See table 1 for variable definitions. $N=257$ bends as defined by the U.S. Geological Survey]

\begin{tabular}{|c|c|c|c|c|c|c|c|}
\hline Dependent variable & Explanatory variable & Estimate & $\begin{array}{c}\text { Standard } \\
\text { error }\end{array}$ & $z$ value & Probability & $\begin{array}{l}\text { Model } \\
\text { AICc }\end{array}$ & Pseudo $r^{2}$ \\
\hline \multicolumn{6}{|c|}{ Initial main-effects model } & 822.83 & 0.648 \\
\hline \multirow[t]{7}{*}{${ }^{1}$ AreaSandPercent } & (Intercept) & -4.89421 & 0.07345 & -66.629 & ${ }^{2} 0.0$ & -- & -- \\
\hline & Bend_avg_RM & 0.03178 & 0.23383 & 0.136 & 0.89199 & -- & -- \\
\hline & SinThalweg & 0.07231 & 0.07742 & 0.934 & 0.35116 & -- & -- \\
\hline & CWidthMean_m & 1.42907 & 0.26627 & 5.367 & ${ }^{2} 1.83 \mathrm{E}-07$ & -- & -- \\
\hline & CWidthStdev_m & 0.34117 & 0.11178 & 3.052 & ${ }^{3} 0.00252$ & -- & -- \\
\hline & DikesPerKm & -0.01507 & 0.1141 & -0.132 & 0.89503 & -- & -- \\
\hline & DikeLengthPerKm & -0.07913 & 0.20029 & -0.395 & 0.69313 & -- & -- \\
\hline \multicolumn{6}{|c|}{ Final model with lowest AIC, main effects and 2-way interactions } & 802.86 & 0.674 \\
\hline \multirow[t]{7}{*}{ 'AreaSandPercent } & (Intercept) & -4.92687 & 0.09037 & -54.519 & ${ }^{2} 2.00 \mathrm{E}-16$ & -- & -- \\
\hline & CWidthMean_m & 1.24009 & 0.1028 & 12.063 & ${ }^{2} 2.00 \mathrm{E}-16$ & -- & -- \\
\hline & CWidthStdev_m & 0.62776 & 0.12622 & 4.973 & ${ }^{2} 1.22 \mathrm{E}-06$ & -- & -- \\
\hline & CWidthMean_m:CWidthStdev_m & -0.46548 & 0.11723 & -3.971 & ${ }^{29.37 \mathrm{E}-05}$ & -- & -- \\
\hline & CWidthStdev_m:Bend_avg_RM & -0.54831 & 0.16559 & -3.311 & ${ }^{3} 0.00107$ & -- & -- \\
\hline & DikesPerKm:DikeLengthPerKm & 0.12813 & 0.06278 & 2.041 & ${ }^{4} 0.04232$ & -- & -- \\
\hline & Bend_avg_RM:SinThalweg & -0.1725 & 0.08742 & -1.973 & ${ }^{4} 0.04958$ & -- & -- \\
\hline
\end{tabular}

${ }^{1}$ The sand variable was transformed by logistic transformation.

${ }^{2}$ Significance $\operatorname{code}=0$.

${ }^{3}$ Significance code $=0.001$.

${ }^{4}$ Significance code $=0.01$. 


\section{Geomorphic Classification and Assessment of the Lower Missouri River for Application to Pallid Sturgeon Management}

Table 4. Linear models to predict presence of age-0 sturgeon.

[AICc, Akaike information criterion, corrected for small sample size; CPUE, catch per unit effort; --, not applicable; “": indicates an interaction between variables; >, greater than. See table 1 for variable definitions. $N=257$ bends as defined by the U.S. Geological Survey]

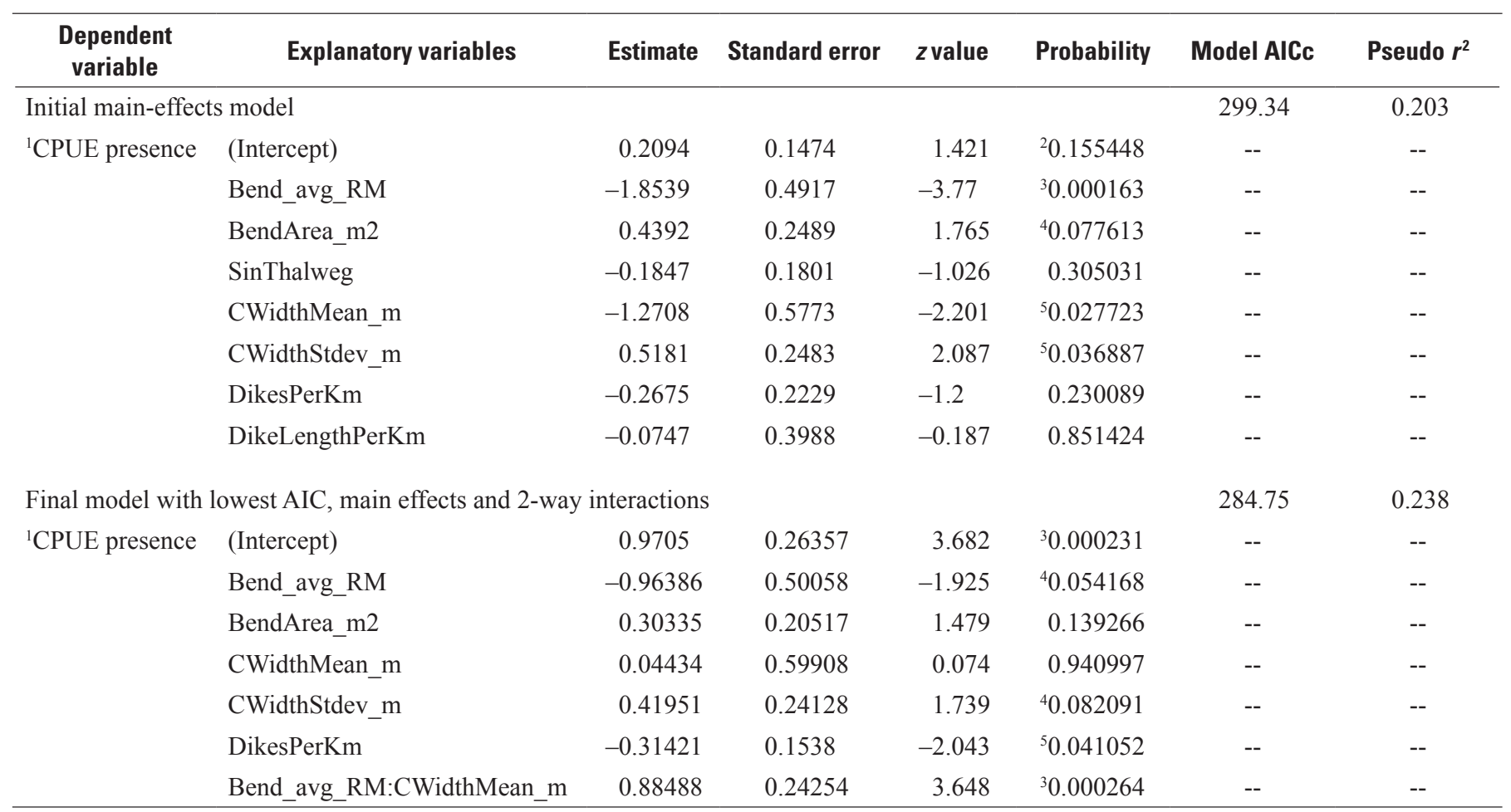

${ }^{1} \mathrm{CPUE}$ presence was calculated by assigning 0 to all zero CPUE bend and 1 to any bend with CPUE $>0$.

${ }^{2}$ Significance code $=0.001$.

${ }^{3}$ Significance code $=0$.

${ }^{4}$ Significance code $=0.05$.

${ }^{5}$ Significance code $=0.01$. 

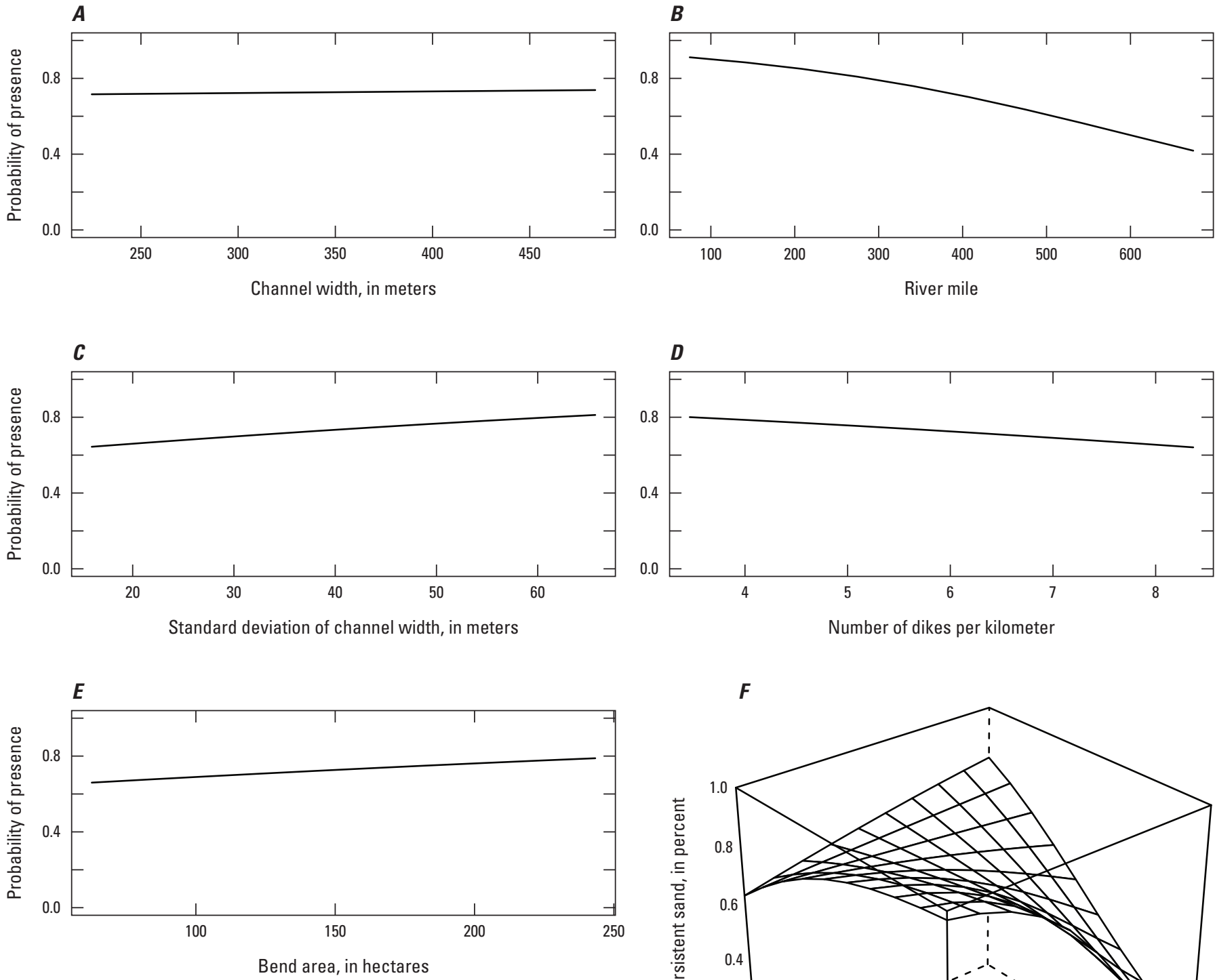

Figure 13. Influence plots for main-effects and interactive variables in final age-0 presence model, showing influence of individual variables while keeping other variables at mean values. $A$, Variation of probability of presence with mean channel width. $B$, Variation of age-0 presence with river mile. $C$, Variation of probability of presence with standard deviation of channel width. $D$, Variation of probability of presence with number of dikes per kilometer. $E$, Variation of age-0 presence with bend area. $F$, Influence plot for interaction of mean channel width and river mile on age-0 presence.

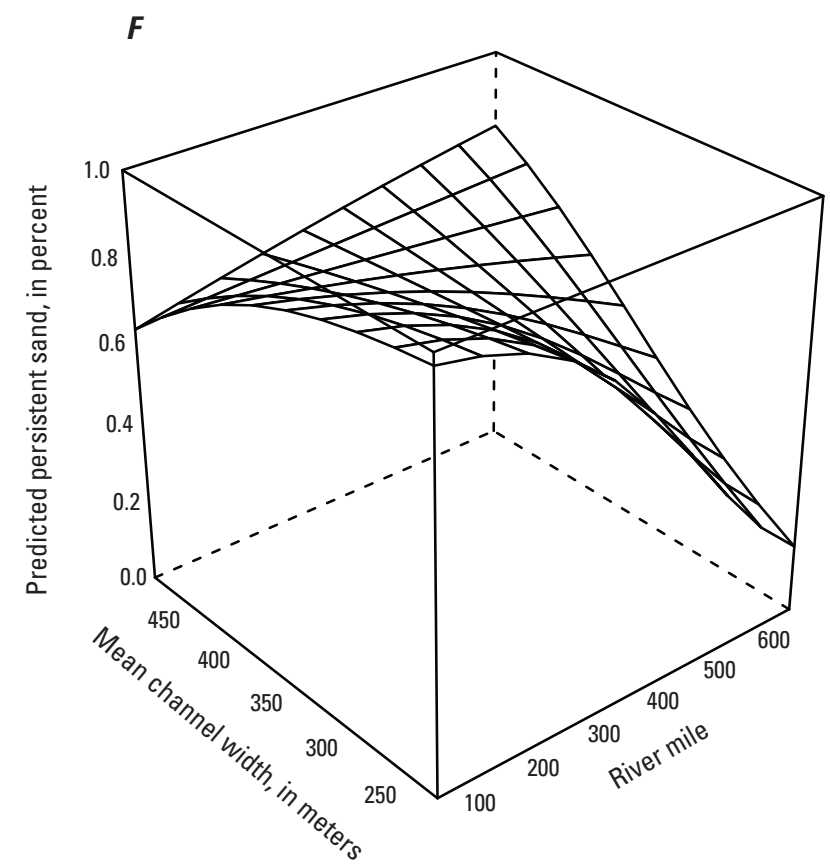

Table 5. Cross-validation table of percent sturgeon presence and absence compared to model-predicted presence and absence, calculated by 5 -fold cross validation.

\begin{tabular}{lcc}
\hline & Actual absence & Actual presence \\
\hline Predicted absence & 78.6 & 21.4 \\
Predicted presence & 25.8 & 74.2 \\
\hline
\end{tabular}


Table 6. Linear models to predict catch per unit effort of age-0 sturgeon, using scaled variables.

[AICc, Akaike information criterion, corrected for small sample size; CPUE, catch per unit effort; <, less than; --, not applicable; e, E: exponentiation; “:” indicates an interaction between variables. See table 1 for variable definitions. $N=139$ bends with catch per unit effort greater than 0$]$

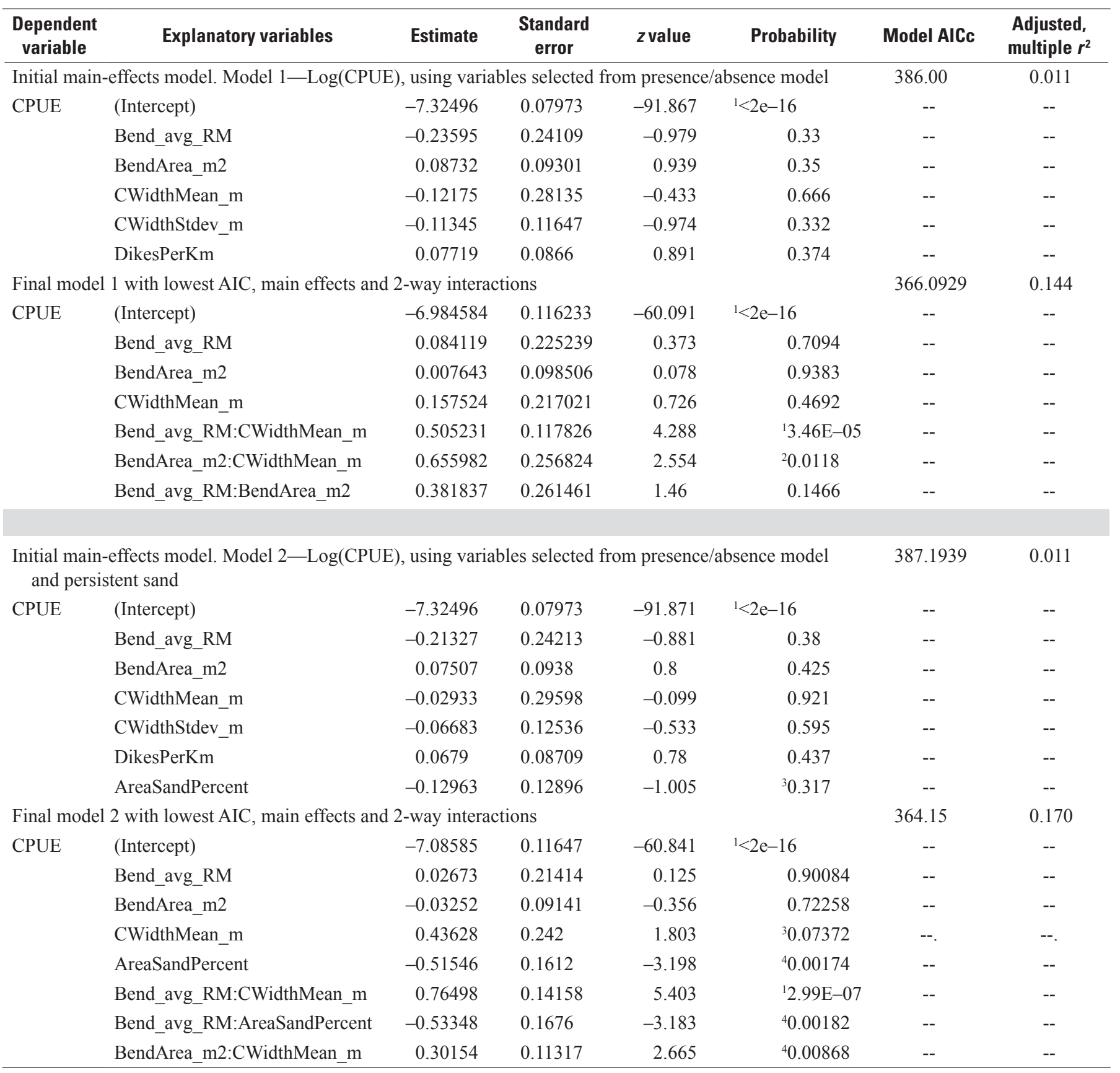

${ }^{1}$ Significance code $=0$.

${ }^{2}$ Significance code $=0.01$.

${ }^{3}$ Significance code $=0.05$.

${ }^{4}$ Significance code $=0.001$. 


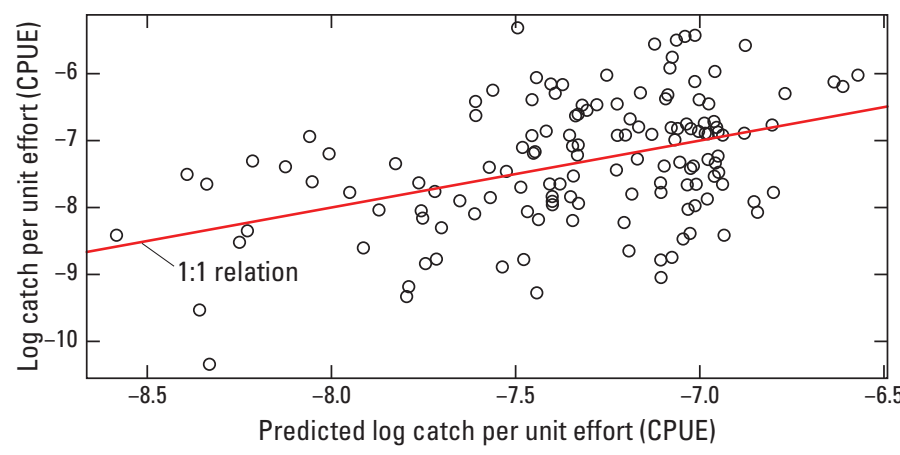

Figure 14. Plot of predicted compared to measured catch per unit effort for age-0 sturgeon for the final model 1 (excluding sand as a predictor variable) with main effects and interactions.
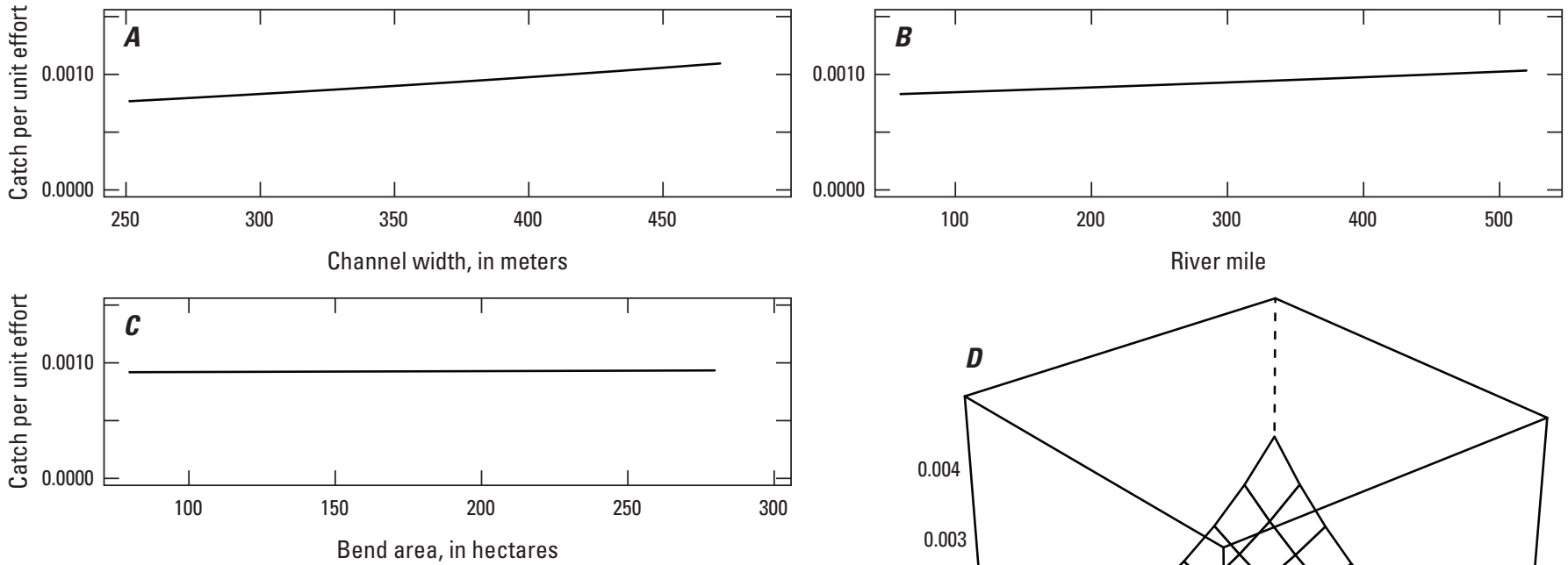

Figure 15. Influence plots for main-effects and interactive variables in final age- 0 catch per unit effort (CPUE) model 1 (without sand), showing influence of individual variables while keeping other variables at mean values.

$A$, Variation of age-0 CPUE with mean channel width. $B$, Variation of age-0 CPUE with river mile. $C$, Variation of age-0 CPUE with bend area. $D$, Variation of age-0 CPUE with interaction of river mile and mean channel width.

$E$, Variation of age-0 CPUE with interaction of bend area and mean channel width. $F$, Variation of age-0 CPUE with interaction of bend area and river mile.
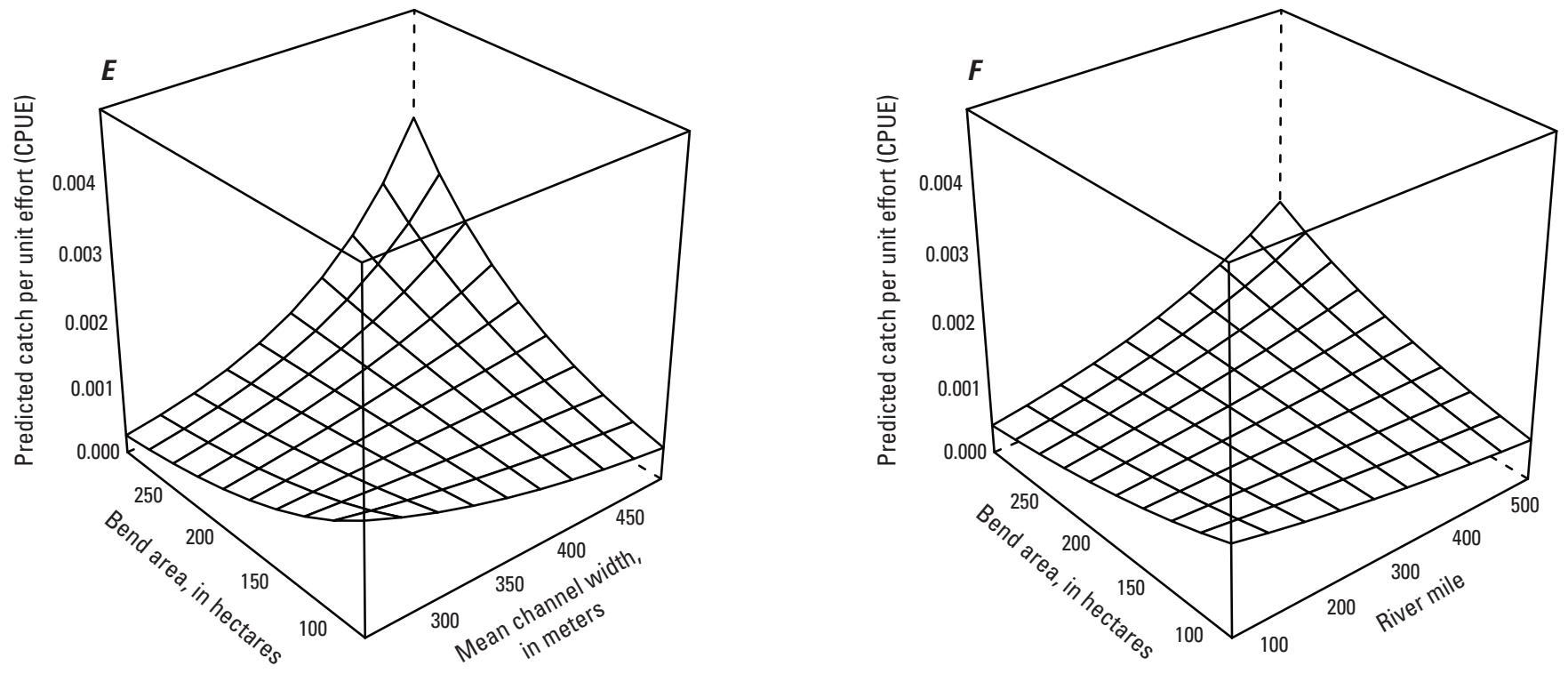


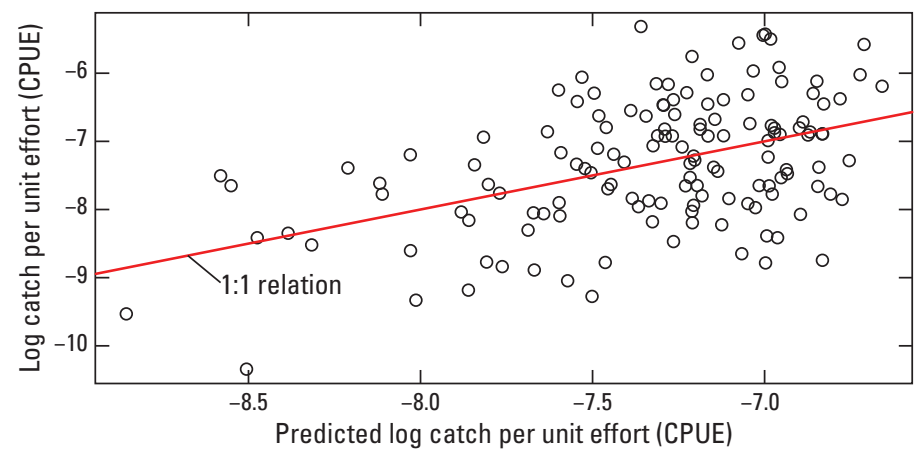

\section{Results}

The clustering analysis for objective 1 and the model exploration analysis for objective 2 were closely interrelated. In the following two sections, we discuss objective 1 and objective 2 results separately. The integrated interpretation of these results is presented in the "Application..." section.

\section{Objective 1-Bend-Scale Geomorphic Classification}

Scatterplots and distributions of prospective explanatory and dependent variables document some salient features of the classification challenge (fig. 3). The first feature is the range of variation in distributions of the variables. Many of the geomorphic variables are highly right skewed or have multiple peaks. The less frequently observed high values of the geomorphic variables are generally consistent with greater channel complexity and likely represent more functional ecosystem processes.

A second feature is that many of the geomorphic variables are correlated. The correlations of variables - and associated collinearity of linear models - is not unexpected because of the tendency of river systems to adjust morphology to prevailing hydrology and sediment supply (Leopold and others, 1964; Schumm, 2005). River-training structures added by the U.S. Army Corps of Engineers are largely independent of the hydrology and sediment supply but are designed to scale with channel size, so they also are correlated with geomorphic variables.

A third feature is the evidence for bivariate correlations between explanatory and potential dependent variables. In particular, the persistent sand variable (AreaPersistentSand) shows increasing relations with the geomorphic and engineering variables (mean channel width, standard deviation of channel width, dikes per kilometer, summed dike length per kilometer). Persistent sand also decreases with increasing river mile (that is, increases in the downstream direction). The CPUE variable has much less visible correlation to the others, except a slight linear increase of CPUE with mean channel width and with persistent sand (fig. 3). All variables except for thalweg sinuosity (SinThalweg) show increasing linear trends
Figure 16. Plot of predicted compared to measured catch per unit effort for age-0 sturgeon for the final model 2 (including sand as a predictor variable) with main effects and interactions. with mean channel width. Physically, this correlation makes sense because wider bends have more space to accommodate navigation structures and sand.

The selection of an optimal number of k-means clusters for classification depends on the nature of the data (how well features are clustered naturally in similar groups) and the intended application of the resulting classification. The scree plot (fig. 4) shows how the sum of squared differences within clusters decreases as more clusters are defined. Typically, changes in the slope of the scree plot are interpreted as indications that additional clusters have decreasing rate of value. The scree plot is fairly continuous, but changes are notable at 3,4 , and 6 clusters. The remaining analyses used these three numbers of clusters to provide a range of lumping/splitting perspectives.

As might be expected in a continuous river system, features at the scale of bends do not cluster into mutually exclusive groups (fig. 5). Instead, clusters overlap substantially, even in multivariate space. Nevertheless, clusters are distinct enough to be of potential utility.

Boxplots of variables by cluster help interpret the physical reality of the clusters (fig. 6; table 7). Although the $\mathrm{k}$-means clustering algorithm does not disaggregate hierarchically like a hierarchical algorithm would, the k-means clustering results in mostly logical subsets of bends that use fewer clusters; therefore, the cells in table 7 are arranged to indicate this hierarchy. In addition to the detailed descriptions in table 7, some salient points about the clustering include the following:

- For the 3- and 4-cluster classifications, the clusters are defined largely by channel size and associated increases in densities of navigation structures. The relative changes in these variables determine cluster assignments.

- In the 6-cluster classification, there is a divergence wherein additional variables begin to determine assignments. For example, cluster 2 (from the 4-cluster classification) was split to delineate newly numbered cluster 4 with somewhat smaller channel width, lower amounts of persistent sand, and increased numbers of dikes per bend. Similarly, cluster 1 (both 3- and 4-cluster classifications) was split in the 6-cluster 

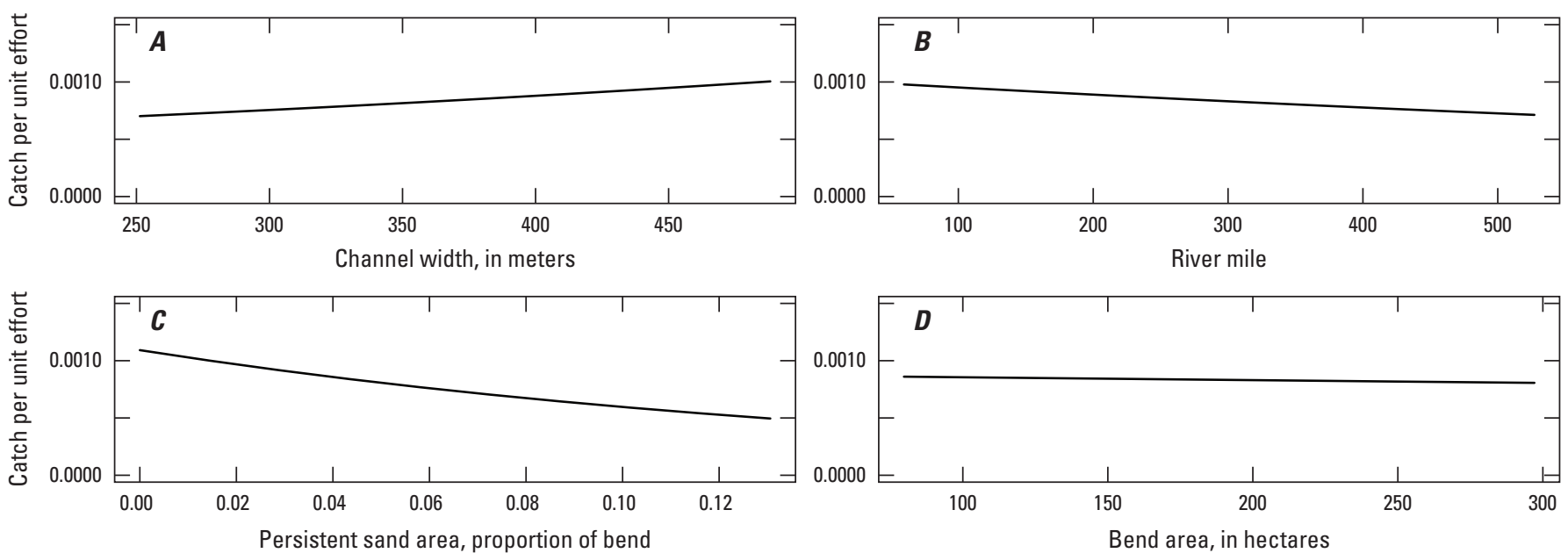

Figure 17. Influence plots for main-effects and interactive variables in final age-0 CPUE model 2 (including sand as a predictor variable), showing influence of individual variables while keeping other variables at mean values. $A$, Variation of age- 0 catch per unit effort (CPUE) with mean channel width. $B$, Variation of age-0 CPUE with river mile. $C$, Variation of age-0 CPUE with persistent sand area. $D$, Variation of age-0 CPUE with bend area. $E$, Variation of age- 0 CPUE with interaction of river mile and mean channel width. $F$, Variation of age-0 CPUE with interaction of bend area and mean channel width. $G$, Variation of age-0 CPUE with interaction of persistent sand and river mile.
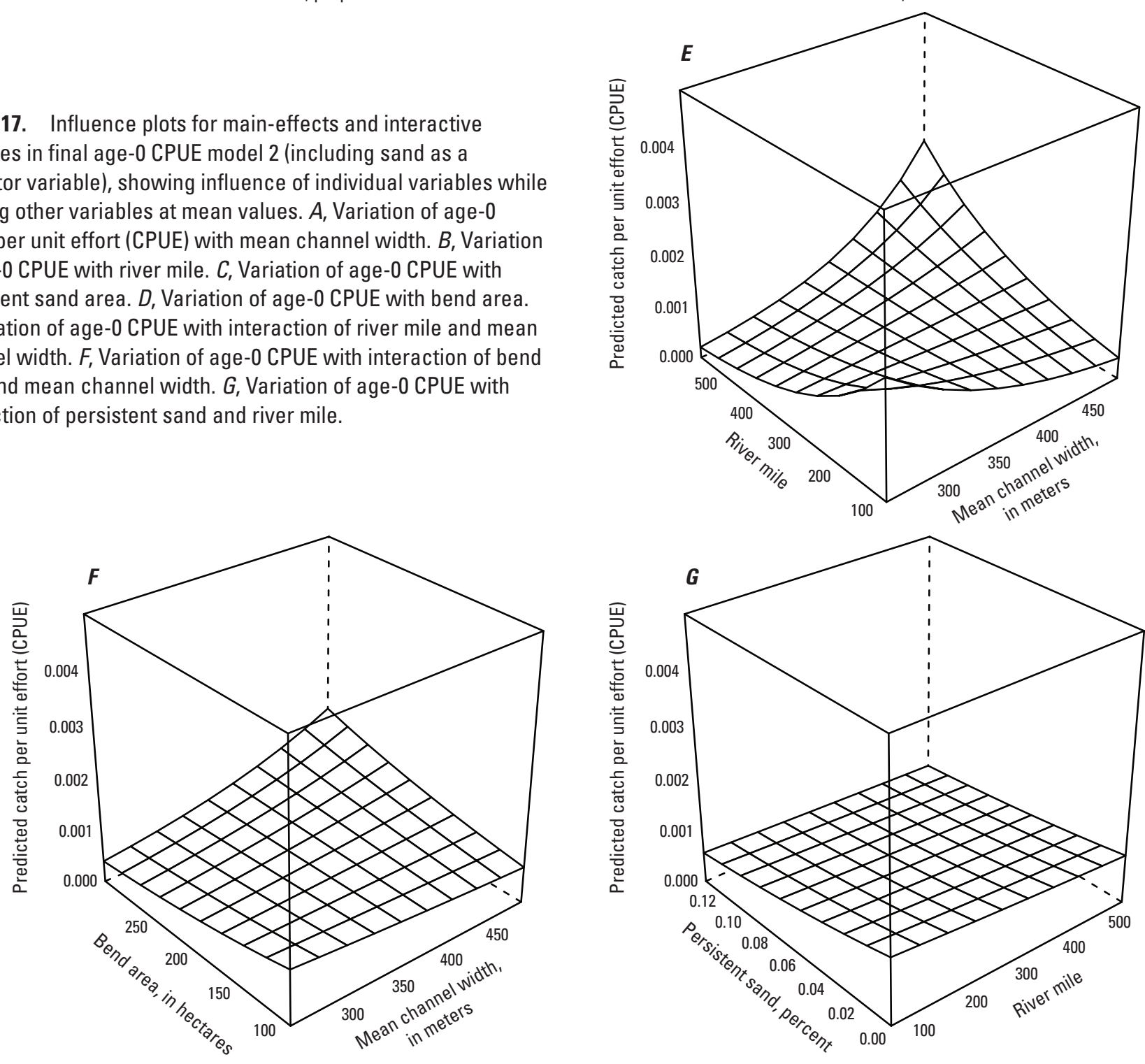
classification to delineate bends with very high sinuosity (newly numbered 1), bends with very low extent of navigation structures (cluster 5), and bends with narrow channels and moderate navigation structures (cluster 6).

- Spatial patterns of clusters are apparent (figs. 7, 8, 9). In all three classifications, the Big Sioux segment and Platte segment (fig. 1) to river mile 550 have similar classes and groups of classes. River mile 550 to 500 stands out in each classification with clusters that have relatively small channel dimensions, low amounts of persistent sand, and relatively high navigation structure density. Breaks in patterns of classes at the Kansas and Grand Rivers may indicate stepwise increases in channel dimensions or other factors related to large increases in drainage area associated with confluences.

\section{Objective 2-Exploration of Relative Interception Capacity}

The multiple regression linear models presented here are intended to explore factors that influence transport of materials (particles, sediment, or organisms) from the thalweg into channel-marginal habitats. The models serve to document the main factors associated with retention of materials and to provide a predictive understanding of where retention is likely to occur.

\section{Persistent Sand Models}

The models using persistent sand (AreaSandPercent) as the dependent variable are fairly robust with pseudo r-square values of 0.648 and 0.674 , respectively, for the models with main effects only and for the AIC-optimized model with main effects and interactions (table 3 ). The coefficients for the maineffects model are highly significant and indicate that persistent sand increases with mean channel width (CWidthMean_m) and standard deviation of channel width (CWidthStdev_m). The final model with 2-way interactions adds complexity to the interpretation. Coefficients for the interaction of mean channel width and standard deviation of channel width, and for the interaction of standard deviation of mean channel width and river mile (Bend_avg_RM) are highly significant $(p<0.0001)$. Two other interactions (dike numbers [DikesPerKm] and dike lengths [DikeLengthPerKm], and river mile and sinuosity [SinThalweg]) are significant at $p<0.05$.

Some insight into the interactions can be provided by examining the plots of individual main effects of the final model while holding all other variables at their mean values (fig. 11). These plots illustrate the strong effects of increasing persistent sand with increasing mean channel width and standard deviation of channel width. The four significant interactions are illustrated in 3-dimensional wireframe plots in which all other variables are kept at mean values (fig. 12). Notable interpretations of these plots include the following:

- The interaction of mean channel width and standard deviation of channel width (fig. 12A) is dominated by mean channel width, but there is a substantive increase in effect of standard deviation of channel width on persistent sand at low channel width compared to high channel width. That is, when other variables are held at their mean values, variable channel width is more effective in producing a higher proportion of persistent sand in narrow channels compared to wider channels.

- Similarly, the interaction of standard deviation of channel width and river mile (fig. 12B) shows that when other variables are held at their mean values the proportion of persistent sand is more sensitive to standard deviation of channel width in downstream areas. This may seem to contradict the previous bullet but results from the fact that this interaction assumes that mean channel width (the dominant variable) is held constant.

- As shown in the plots of interactions of thalweg sinuosity and river mile (fig. $12 C$ ), and dike length density and dike number density (fig. 12D), these interactions are subtle, even if statistically significant.

The interactions developed in the final model are a measure of the complexity of physical processes operating in the river system (fig. 12). The models present information that may be best treated as hypotheses that should be tested in a field-based, deterministic framework.

\section{Catch Per Unit Effort Models}

The presence/absence models for age- 0 sturgeon CPUE (that is, $\mathrm{CPUE}=0$ or CPUE greater than $[>] 0$ ) have pseudo r-square values substantially less than that of the persistent sand models (tables 3,4), indicating the generally decreased ability of these variables to explain catch of age-0 sturgeon. The classification matrix (table 5) serves as an additional measure of utility of the model and indicates that accuracy in predicting absence is about 79 percent and in predicting presence is about 74 percent, assuming a threshold for presence of 0.5 and greater. The main-effects and final (AIC-optimized) models have several significant variables. In the main-effects model, the probability of CPUE $>0$ decreases significantly with increasing river mile and mean channel width; probability of CPUE $>0$ increases significantly with standard deviation of channel width. In the AIC-optimized model with 2-way interactions, probability of CPUE $>0$ decreases with river mile, but the coefficient does not meet significance at $p=0.054$. Unlike the main-effects model, however, dike density (number of dikes per kilometer) becomes significant in the interactions model and probability of CPUE $>0$ decreases with increasing dike density (table 4, fig. 13). The effects of variables and 
Results

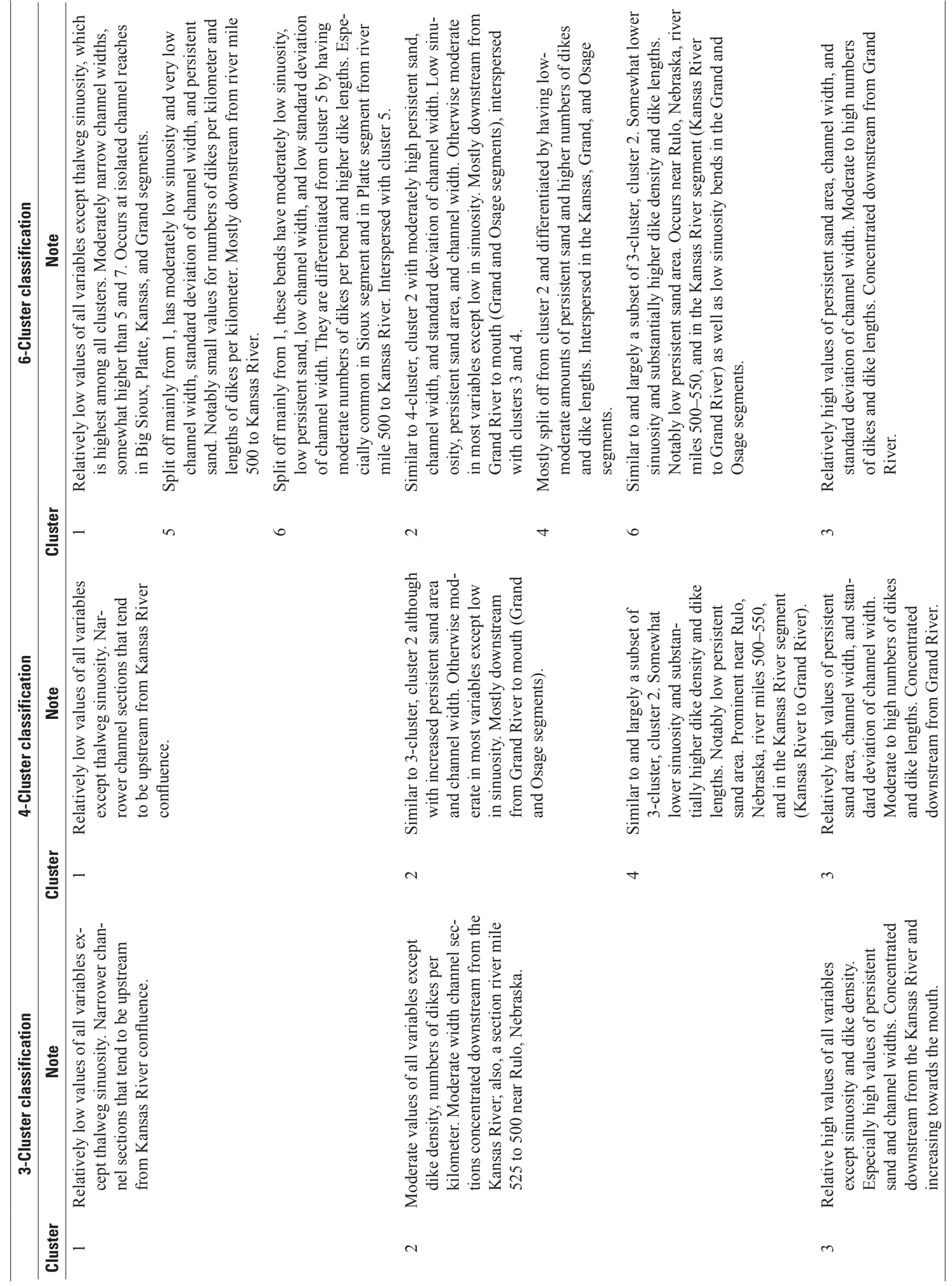


interactions can be seen in plots of predicted probabilities by individual variables while assigning other variables to their mean values (fig. 13). The interaction between river mile and mean channel width is highly significant in the AIC-optimized model (fig. 13F). The interaction indicates that if channel widths are large in upstream areas the probability of presence would be greater than 0.8 ; however, widths greater than $300 \mathrm{~m}$ are rare upstream from river mile 400 (fig. 3).

\section{CPUE Model 1-CPUE with Physical Variables}

The first model explored for bends with CPUE $>0$ started with all the physical variables that were used in the presence/ absence model (table 6). In the initial main-effects model, only the intercept was significant and the adjusted multiple r-square value was 0.011 . Adding in 2-way interactions and stepping through the models to optimize based on AIC resulted in a model with three main-effects variables (although not significant) and two significant interactions. The adjusted multiple $r$-square improved to 0.144 . Although interpretation is challenging in models with interactions, it is notable that CPUE increases with increasing mean channel width (fig. 15A), but the model does not indicate a significant relation (table 6). It is also notable that CPUE decreases with river mile (upstream) in the main-effects model (table 6, but with low significance at $p=0.33$ ), whereas CPUE increases with river miles when all other variables are assigned mean values (fig. 15B). Relations that seem to be contradictory are not unexpected with models with low explanatory power.

The interaction between river mile and mean channel width indicates that lower in the river system, where widths tend to be higher, smaller widths are associated with greater CPUE (fig. 15D). Similarly, in upstream areas where widths tend to be smaller, larger widths are associated with increased CPUE. The interactions between mean channel width and bend area and between river mile and bend area are very similar, indicating that anomalous river widths or bend areas are likely to have greater CPUE.

\section{CPUE Model 2-CPUE with Physical Variables and Persistent Sand}

The second model added in persistent sand as a potential explanatory variable (table 6). The rationale for including persistent sand area is that periods and characteristics of transport of free embryos and sand are likely to be dissimilar enough that measured persistent sand might be a useful independent variable for where free embryos are retained. By comparison of adjusted multiple r-square values, the addition of persistent sand seemed to increase the predictive capacity of the model. The adjusted multiple r-square increased from 0.144 to 0.170 for the optimized model with 2-way interactions. Similar to the previous model, only the intercept was significant in the main-effects model. In the model that includes interactions, the coefficient for persistent sand is significant $(p=0.002)$ and the coefficient for mean channel width is nearly significant $(p=0.074)$. It is notable, however, that contrary to expectations, CPUE decreases with increasing persistent sand but increases with mean channel width (figs. 17A, C). The decrease of CPUE with increasing persistent sand may be interpreted as the effect of large amounts of sand, presumably at relatively high elevations, diminishing the interception capacity of the bend. Extensive sandbars that are frequently emergent would also be less likely to have successful trawls. The interactions between river mile and mean channel width and between bend area and mean channel width continue the pattern of anomalies having higher CPUE compared to average conditions (fig. 17E, F). The interaction between persistent sand and river mile is notable because CPUE rises with river mile at low sand area but declines with river mile when sand area is high (fig. 17G).

\section{Application of Bend-Scale Geomorphic Classification of the Lower Missouri River}

The primary objective of this research was to develop a statistical classification of channel characteristics of the Lower Missouri River at the bend scale. The second objective was to use CPUE data for age- 0 sturgeon catches, and persistent sand area as a surrogate, to explore which bend-level variables are more highly associated with elevated CPUE.

\section{Application of Bend Classification}

By using standard analytical tools (k-means clustering) over a range of cluster numbers, we have been able to provide a classification based on objective analysis of channel-scale data. Selection of the 3-, 4-, or 6-cluster classification would depend on to specific questions or applications.

Presently (spring 2018), there is a need for a classification system that can be used in sample designs for monitoring performance of constructed IRCs. A staircase-based BACI design has been proposed to monitor and evaluate IRCs (Fischenich and others, 2017). Implementation of the monitoring design requires some assurance that control and intervention sites are sufficiently alike to provide useful comparisons. The bendscale classification presented here can be used to select control and implementation sites from the same cluster class.

Also, planning decisions related to IRCs, and perhaps other restoration objectives, may benefit from insights into how processes vary by bend class. Physical interpretation of the classes developed through k-mean clustering provides some predictive understanding of how processes are likely to vary. In addition, modeling of sand area and CPUE response variables provides initial exploration of what variables may be most influential in creating habitat or intercepting drifting larvae (or perhaps intercepting other items in transport like contaminants or invertebrate drift). These insights may be used to decide whether restoration investments would be best 
applied to bends with low potential capability to trap sand or larvae or to improve bends that are already performing well.

A decision to use the 3-, 4-, or 6-cluster classification will likely depend on application. For example, in application to IRC statistical sampling design, there is a tradeoff between achieving a closer match between control and intervention reaches and loss of statistical power that would result from increased stratification (more clusters). The IRC design process, therefore, may elect to use the 3- or 4-cluster classification. When applied to increased understanding of processes responsible for differential transport or retention, the more detailed 6-cluster classification may be more useful. In addition, the identification of 3,4 , and 6 clusters, although based on graphical properties of the scree plot (fig. 4), was somewhat arbitrary; additional classifications with different numbers of clusters might be useful and could be generated from the released datasets (Jacobson, 2017).

\section{Application of CPUE Multiple Regression Models}

The high pseudo r-squared values for persistent sand models indicate that they perform well in predicting where sand accumulates along the Lower Missouri River (table 3). The final optimized model shows that mean channel width and standard deviation of channel width are highly significant and have relatively large effect on persistent sand (table 3, figs. 11A, B). The interaction of mean channel width and standard deviation of channel width (fig. $12 A$ ) indicates that proportional sand area increases with both variables. The interaction between river mile and standard deviation of channel width indicates that variability in width is more effective in increasing sand retention in downstream reaches (fig. 12B). These results support the physical interpretation that accommodation space (channel width) is a primary requirement for sand retention, whereas accumulation (and retention) is favored by variability in channel width that increases secondary currents and flow expansion.

Other interactions in the final model (figs. $12 C, D$ ) show smaller effects. The interaction between thalweg sinuosity and river mile is notable because it indicates that sand persistence is more sensitive to sinuosity (and presumably secondary currents associated with sinuosity) in upstream, narrower reaches compared to downstream. The interaction between dike number per kilometer and dike length per kilometer is significant ( $p=0.042$; table 32 ), although the effect seems small (fig. 12D). This result is of interest because it indicates that in its present configuration, the channel's engineering structures do not seem to be a primary control on where sand accumulates. This result may arise because the metrics to evaluate engineering structures (number density and length density) lack the ability to discriminate the effects of structures on transport dynamics. The integrated effects of structures may instead be captured in the variables for mean channel width and standard deviation of channel width.
These relations indicate that channel widening and increasing variation in channel width (increasing flow expansion potential) may provide the secondary currents and accommodation space needed for complex habitats associated with sandbars; however, in bends that are already widened, increased emphasis might be placed on altering wing-dike geometries to achieve secondary flow structures through constriction and expansion. The bend-scale analysis presented in this report does not extend to the resolution of individual navigation structures, and results are only suggestive of how within-bend changes to training structures could affect sand advection into channel-marginal areas.

Although an understanding of segment-scale controls on sand persistence is useful for habitat assessment and restoration designs, a more acute challenge is to understand the controls on potential of bends to intercept drifting sturgeon larvae. As shown in this report, CPUE models seem to be uniformly poor performers compared to those that predict persistent sand. This conclusion is subject to the caveat that the most obvious comparison is between pseudo r-squared values for sand models compared to multiple r-squared values for CPUE models, which is a comparison that lacks precision because the two r-squared metrics are calculated in different ways. Nevertheless, sand seems to be much more predictable compared to CPUE of age-0 sturgeon.

Among the CPUE models, the presence/absence models (table 4) have the highest r-squared values, and the high classification rate of the final presence/absence model (table 5) supports its utility. The main-effects and AIC-optimized model with interactions both indicate a significant, or nearly significant, increase in probability of CPUE $>0$ downstream (table 4 , fig. 13B), which is consistent with downstream transport of larvae at this age when they are mostly transported passively by the current (DeLonay and others, 2016). Probability of CPUE $>0$ decreases significantly with dikes per kilometer, which may be explained by either the transport mechanics, which require space between wing dikes for completion of secondary velocity vectors (flow expansions), or by decreased capture efficiency where wing dike spacing is too short to effectively deploy benthic trawls. The significant interaction between river mile and mean channel width (table 4, fig. $13 F$ ) indicates that for narrow channels, probability of CPUE $>0$ decreases substantially in the upstream direction. Conversely, in downstream reaches, probability of CPUE $>0$ decreases with increasing mean channel width, which is a result that may be explained by a scale-dependent capture efficiency in which age-0 sturgeon are less likely to be sampled in wider bends where the fish are widely spatially distributed. The indication that probability of CPUE $>0$ would increase for channel widths $>400 \mathrm{~m}$ in upstream reaches is an unlikely scenario because widths $>300 \mathrm{~m}$ are rare upstream from river mile 500 .

Among bends with CPUE $>0$, the models to predict CPUE have multiple r-squared values of 0.011 to 0.170 , with models using interactions having substantially greater values compared to main-effects-only models. Given the low predictive ability of the models, there may be little information value in 
the individual coefficients and interactions. Lack of a significant upstream-downstream effect may be explained by the shifting of spawning locations and transport rates through time. The general understanding of drift and development of Scaphirhynchus sturgeon indicates that drifting free embryos transition to first feeding and will "settle" to a benthic orientation in appropriate channel-marginal habitats if those habitats are accessible (DeLonay and others, 2016; Jacobson and others, 2016). Transition occurs 9-14 days post hatch as the fish uses up its yolk-sac food reserves and develops the ability to swim, hold position, and forage for food items. Spawning sites where drift originates in any given year are unknown, and spawning of pallid sturgeon has been detected at a wide variety of main-stem sites ranging over 500 river miles. Moreover, although undifferentiated in the CPUE dataset, most of the age-0 sturgeon are assumed to be shovelnose sturgeon, which are thought to spawn over a wider range of conditions and in tributaries (Keenlyne, 1997); therefore, the catch in the 9-year dataset likely includes progeny from fish that spawned over a range of times and locations in the main stem and tributaries of the Missouri River. Variability in those spawning locations and development rates (varying with water temperatures) would be expected to provide a wide range of locations along the main stem where transition to first feeding would occur. Spawning location and drift distance are expected to exert first-order controls on where age- 0 sturgeon would be retained, whereas the geomorphic and hydraulic conditions of bends would exert a secondary control, either enhancing or diminishing the ability of fish to access supportive channel-marginal habitats. It should be noted that hydraulic influences vary year to year as well, and some of the variation in the CPUE dataset is likely due to hydroclimatic variation that would influence interception and retention during drift.

The interaction of spawning origin, transport, and interception hydraulics may explain the general trend noted in CPUE and sand accumulations along the river (fig. 2).

Whereas persistent sand and channel dimensions continue to increase downstream, CPUE plateaus at river mile 200-400 and then declines from river mile 200 to the mouth at river mile 0. It is possible that the peak and decline in CPUE relates in part to interception of age- 0 sturgeon at locations where they have reached transition rather than bend-scale hydraulics; that is, bend-scale hydraulics from river mile 0-200 may be conducive to interception, but the populations of drifting larvae could be already intercepted upstream. Alternatively, CPUE may decrease as the channel increases in dimensions for a variety of other reasons including changes in gear efficiency (see below) or other biophysical reasons. Moreover, because spawning locations are unknown, predictive understanding of where age- 0 fish are likely to be retained is inherently limited. Notably, locations of persistent sand are more amenable to prediction because sand is much more abundant and fate is not tied to a site of origin.

The second CPUE model improved marginally when persistent sand area was added as an explanatory variable (table 6). The coefficient for persistent sand was non-significant at the $p=0.05$ level in the main-effects model ( $p=0.317$ ) but became significant in the model with interactions ( $p=0.0017$ ). Interestingly, the sign on the coefficient is negative, indicating that CPUE tends to decrease with increasing persistent sand area (table 6, fig. 17C). The model also indicates that mean channel width is barely non-significant at the $p=0.05$ level $(p=0.074)$ and when other variables are held at their mean values, CPUE increases with mean channel width (fig. 17A). Together, these trends indicate that wider bends that do not accumulate sand may have greater retention of age- 0 sturgeon. The negative relation between persistent sand and CPUE may indicate that narrower bends with too much sand have less interception potential for larvae or less opportunity to trawl.

The bend-scale classification and modeling presented here provide a framework for understanding Lower Missouri River habitat processes and for designing monitoring and evaluation programs. The persistent sand models document systematic and predictive relations between channel morphological variables and sand accumulations. To the extent that transport and accumulation of age- 0 sturgeon larvae are also controlled by physical processes, we would expect the same channel morphological variables to predict CPUE. The poor performance of the CPUE models is evidence that there are shortcomings in current understanding of drift processes (uncertain drift origin, mediation by active swimming, potential gear biases, for example). Notwithstanding poor prediction of CPUE, a design decision might be made to use sand as a surrogate based on the assumption that sand distributions show the long-term distribution of channel-marginal habitat and habitat complexity and the potential for accumulation of larvae, albeit possibly unrealized. This habitat-centric view may provide an initial pathway for locating channel reconfiguration projects, but validation would ultimately require measurements of biological response.

\section{Combining Information From Bend Classification and CPUE Models}

Consideration of the 6-cluster classification and the CPUE presence/absence model provides some guidance for selecting bends for channel reconfiguration. The relations plotted in figure 13 (based on keeping other variables at their mean values) show probability of CPUE $>0$ decreasing with river mile and number of dikes per kilometer while increasing with standard deviation of channel width and bend area. Of these variables, dike density is significant at $p=0.05(p=0.041)$ and river mile and standard deviation of channel width are barely non-significant ( $p=0.054$ and 0.082 , respectively). Among the 6-cluster classes, no class has high representations of both channel morphological variables. Cluster 3 has the highest standard deviation of channel width and would, therefore, be a candidate for having a high capacity for retention of age-0 sturgeon; however, cluster 3 also has a relatively high number of dikes per kilometer (fig. 6). Conversely, cluster 5 
has the lowest dike density but also a low standard deviation of channel width.

These relations make physical sense because bends with greater width variability and associated habitat diversity tend to require larger numbers of dikes to maintain the navigation channel. Those bends with little variability in channel width do not require large numbers of dikes for maintenance. The relations indicate that in cluster 3 , channel reconfiguration designs that would decrease dike density would increase CPUE. In cluster 6 bends, designs to increase width variation would increase CPUE. These relations provide some general guidelines based on the statistical analysis presented, but specific designs would need to account for bend-specific hydraulic considerations.

\section{Extension of Bend-Scale Understanding}

Improvements to prediction of where age- 0 sturgeon are likely to be retained on the Lower Missouri River-and where channel reconfigurations will be most effective-will require additional understanding at two distinct scales. At the landscape scale, improvement in understanding of where sturgeon spawn is critical to predicting where their larvae are likely to settle. This improvement will require additional effort in tracking reproductive adults to spawning sites and validation of successful reproduction. In addition, refinement and validation of physical models for larval transport (Fischenich and others, 2014; Bulliner and others, 2016) will need to be coupled with improved understanding of ontogenetic development of free embryos and larvae that can account for changes in swimming ability between hatch and settling. These factors are not well quantified and may substantially influence how far a larva will drift before it develops to the point where it can hold itself in moderate current and therefore be retained in an IRC.

An additional unknown related to segment-scale dispersal and bend-scale interception is where in the water column developing larvae are likely to drift. Hatchery and laboratory observations indicate persistent vertical swim-up and fall behaviors of free embryos soon after hatch (Kynard and others, 2004; DeLonay and others, 2016). Catch rates of free embryos in natural rivers, however, are consistently greatest within $1 \mathrm{~m}$ of the bottom (Braaten and others, 2012). The challenge is to reconcile laboratory and field observations of drift height, and how drift height varies with development, to understand effective transport velocities and to improve designs of interception at the bend scale.

The second scale is for individual bends or parts of bends and relates to details of hydraulics and transport. The approach used in this analysis is based on bend-scale measures of channel geomorphology. The measures certainly relate to details of hydraulics, transport, and deposition within the bends, but we recognize that they are indices rather than high-resolution metrics. In addition to improved biological understanding of drift processes, improvement in physical assessment tools would also be useful for decreasing uncertainties. For example, multidimensional hydrodynamic models and particle-tracking algorithms exist that can be used to evaluate explicitly how sediment and larvae will be transported from segment to bend scale. Although particle tracking is computationally intensive, the main impediment to developing extensive multidimensional hydrodynamic models continues to be a lack of highresolution bathymetric data for creation of segment-scale computational meshes. Utilization of particle tracking, driven by well-calibrated hydrodynamic models at the segment scale, would move understanding of larval transport and fate from correlation to causality.

\section{Summary and Conclusions}

Management actions to avoid jeopardy to the pallid sturgeon (Scaphirhynchus albus) on the Lower Missouri River require an understanding of how pallid sturgeon life stages and habitat requirements are distributed along the river in relation to habitat availability. The present study had two related objectives. The first objective was to develop a bend-scale geomorphic classification of the Lower Missouri River to help in the design of monitoring and evaluation of channel reconfiguration projects. The classification was based on a set of geomorphic and navigation-structure variables compiled at the bend scale for 257 bends from Sioux City, Iowa, to the confluence with the Mississippi River near St. Louis, Missouri. A k-means clustering approach led to three somewhat nested classifications based on 3, 4, and 6 naturally occurring clusters of the geomorphic data.

The second objective was to explore whether the geomorphic variables could provide insight into models and variables that would explain relative capacity for bends to intercept drifting larvae. We explored this objective by evaluating alternative models that predicted persistent sand area or catch per unit effort (CPUE) of age-0 sturgeon as a function of geomorphic variables. Persistent sand increased with mean channel width and standard deviation of channel width. Additional interactions among variables also emerged in the optimized model, indicating the complexity of geomorphic and hydraulic processes occurring at the bend scale.

The CPUE of age- 0 sturgeon is a more elusive variable because of variation based on spawning location, varying transport dynamics over the sampling period, and uncertainties inherent in sampling in large rivers. Probability of CPUE greater than $(>) 0$ decreased upstream and with dike density (number of dikes per kilometer) and increased (although the coefficient was not significant) with standard deviation of channel width. For bends with CPUE $>0$, linear models were less predictive. Models indicated that CPUE decreases with area of persistent sand and increased less significantly with increases in mean channel width.

None of the classified clusters had the combinations of variables that the CPUE models indicated would maximize CPUE. Cluster 3 had high standard deviation of channel width 
but also had high dike density. In comparison, cluster 5 had the lowest dike density but also very low standard deviation of channel width. The lack of correspondence may indicate design opportunities to decrease dike densities in cluster 3 and increase channel width variability in cluster 5.

Improvements to predictions of where age-0 sturgeon are likely to settle from the drift will depend on improvements to biological understanding in two ways. Spawning sites determine the beginning of the transport process, so locating spawning sites in time and space continues to be fundamental to understanding reproductive ecology of sturgeon in the Missouri River. In addition, developmental factors that determine acquisition of mobility and vertical distribution in flow field are critical to understanding the details of how flow fields will interact with channel geometry to determine settling sites. As biological understanding improves, the value of bend-scale geomorphic classification will increase.

\section{References Cited}

Afshartous, D., and Preston, R.A., 2011, Key results of interaction models with centering: Journal of Statistics Education: Journal of Statistics Education, v. 19, no. 3, p. 1-24. [Also available at https://doi.org/10.1080/10691898.2011.1 1889620.]

Bemis, W.E., and Kynard, B., 1997, Sturgeon rivers-An introduction to acipenseriform biogeography and life history: Environmental Biology of Fishes, v. 48, no. 1, p. 167-183. [Also available at http://dx.doi.org/10.1023/A:1007312524792.]

Braaten, P.J., Fuller, D.B., Lott, R.D., Ruggles, M.P., Brandt, T.F., Legare, R.G., and Holm, R.J., 2012, An experimental test and models of drift and dispersal processes of pallid sturgeon (Scaphirhynchus albus) free embryos in the Missouri River: Environmental Biology of Fishes, v. 93, no. 3, p. 377-392, [Also available at http://dx.doi.org/10.1007/ s10641-011-9925-9.]

Bulliner, E.A., Erwin, S.O., Jacobson, R.B., Chojnacki, K.A., George, A.E., and DeLonay, A.J., 2016, Identifying sturgeon spawning locations through back-calculations of drift, in Constantinescu, G., Garcia, M., and Hanes, D., eds., River flow 2016: London, Taylor and Francis Group, p. $2188-2196$.

Burnham, K.P., and Anderson, D.R., 2002, Model selection and multimodel inference-A practical informationtheoretic approach: New York, N.Y., Springer, 488 p.
DeLonay, A.J., Chojnacki, K.A., Jacobson, R.B., Albers, J.L., Braaten, P.J., Bulliner, E.A., Elliott, C.M., Erwin, S.O., Fuller, D.B., Haas, J.D., Ladd, H.L.A., Mestl, G.E., Papoulias, D.M., and Wildhaber, M.L., 2016, Ecological requirements for pallid sturgeon reproduction and recruitment in the Missouri River-A synthesis of science, 2005 to 2012: U.S. Geological Survey Scientific Investigations Report 2015-5145, 224 p. [Also available at http://dx.doi.org/10.3133/sir20155145.]

Driscoll, R.S., Merkel, D.L., Radloff, D.L., Snyder, D.E., and Hagihara, J.S., 1984, An ecological land classification framework for the United States: U.S. Department of Agriculture, U.S. Forest Service, Miscellaneous Publication $1439,56 \mathrm{p}$.

Elliott, C.M., and Jacobson, R.B., 2006a, Geomorphic classification and assessment of channel dynamics in the Missouri National Recreational River, South Dakota and Nebraska: U.S. Geological Survey Scientific Investigations Report 2006-5313, 66 p. [Also available at http://pubs.er.usgs.gov/ usgspubs/sir/sir20065313.]

Elliott, C.M., Jacobson, R.B., and Freeman, M.C., 2014, Stream classification of the Apalachicola-ChattahoocheeFlint River System to support modeling of aquatic habitat response to climate change: U.S. Geological Survey Scientific Investigations Report 2014-5080, 79 p. [Also available at http://dx.doi.org/10.3133/sir20145080.]

Fischenich, J.C., Buenau, K.E., Bonneau, J.L., Fleming, C.A., Marmorek, D.R., and Gemeinhardt, T.R., 2017, Science and Adaptive Management Plan appendices and attachmentsDraft 6: Missouri River Recovery Program ERDC/EL TRXX-DRAFT, $538 \mathrm{p}$.

Fischenich, J.C., McComas, R., Meier, D., Tripe, J., Pridal, D., Boyd, P., Gibson, S., Hickey, J., Econopouly, T., and Strong, L., 2014, Hydrologic, hydraulic, and geomorphic models and analyses to support the Missouri River Effects Analysis: U.S. Army Corps of Engineers, Engineer Research and Development Center, 148 p.

Frissell, C.A., Liss, W.J., Warren, C.E., and Hurley, M.D., 1986, A hierarchical framework for stream habitat classification-Viewing streams in a watershed context: Environmental Management, v. 10, no. 2, p. 199-214. [Also available at http://dx.doi.org/10.1007/BF01867358.] 
Harrison, A.B., 2012, The diets of larval and juvenile pallid sturgeon and shovelnose sturgeon (Scaphirhynchus spp) in the lower Mississippi River: Clemson, S.C., Clemson University, M.S. thesis, 79 p.

Hosmer, D.W., and Lemeshow, S., 2000, Applied logistic regression: New York, John Wiley and Sons, 383 p. [Also available at https://doi.org/10.1002/0471722146.]

Jacobson, R.B., 2017, Missouri River bend classification datasets: U.S. Geological Survey data release, accessed November 2017 at https://doi.org/10.5066/F7FF3R9D.

Jacobson, R.B., Annis, M.L., Colvin, M.E., James, D., Welker, T.L., and Parsley, M.J., 2016, Missouri River Scaphirhynchus albus (pallid sturgeon) effects analysis - Integrative report 2016: U.S. Geological Survey Scientific Investigations Report 2016-5064, 154 p. [Also available at http://dx.doi.org/10.3133/sir20165064.]

Jacobson, R.B., Elliott, C.M., and Huhmann, B.L., 2010a, Development of a channel classification to evaluate potential for cottonwood restoration, lower segments of the Middle Missouri River, South Dakota and Nebraska: U.S. Geological Survey Scientific Investigations Report 2010-5208, 38 p., [Also available at http://pubs.usgs.gov/ $\operatorname{sir} / 2010 / 5208$.]

Keenlyne, K.D., 1997, Life history and status of the shovelnose sturgeon, Scaphirhynchus platorynchus: Environmental Biology of Fishes, v. 48, no. 1-4, p. 291-298. [Also available at http://dx.doi.org/10.1023/A:1007349221987.]

Kondolf, G.M., Montgomery, D.R., Piegay, H., and Schmitt, L., 2003, Geomorphic classification of rivers and streams, chap. 7 of Kondolf, G.M., and Piegay, H. eds., Tools in fluvial geomorphology: Chichester, United Kingdom, John Wiley \& Sons, p. 171-204.

Kynard, B., Parker, E., Pugh, D., and Parker, T., 2004, Swimming height and the effect of velocity on dispersal of free embyro and larval pallid sturgeon-An experimental study: Prepared for the U.S. Army Corps of Engineers, Omaha District, 29 p.

Leopold, L.B., Wolman, M.G., and Miller, J.P., 1964, Fluvial processes in geomorphology: San Francisco, Calif., W.H. Freeman and Co., 544 p.
Poulton, B.C., Wildhaber, M.L., Charbonneau, C.S., Fairchild, J.F., Mueller, B.G., and Schmitt, C.J., 2003, A longitudinal assessment of the aquatic macroinvertebrate community in the channelized Lower Missouri River: Environmental Monitoring and Assessment, v. 85, no. 1, p. 23-53. [Also available at http://dx.doi.org/10.1023/A:1023301016001.]

R Development Core Team, 2013, R-A language and environment for statistical computing: Vienna, Austria, R Foundation for Statistical Computing, accessed June 2017 at http://www.R-project.org/.

Ridenour, C.J., Doyle, W.J., and Hill, T.D., 2011, Habitats of age-0 sturgeon in the Lower Missouri River: Transactions of the American Fisheries Society, v. 140, no. 5, p. 1351-1358. [Also available at http://dx.doi.org/10.1080/00028487.2011.620493.]

Rosgen, D.L., 1994, A classification of natural rivers: Catena, v. 22, no. 3, p. 169-199. [Also available at https://doi.org/10.1016/0341-8162(94)90001-9.]

Rowe, J.S., 1962, Soil, site and land classification: Forestry Chronicle, v. 38, no. 4, p. 420-432. [Also available at https://doi.org/10.5558/tfc38420-4.]

Schumm, S.A., 2005, River variability and complexity: Cambridge, United Kingdom, Cambridge University Press, 234 p. [Also available at https://doi.org/10.1017/ CBO9781139165440.]

Sechler, D.R., 2010, Effect of abiotic and biotic factors on diet composition of age-0 sturgeon (Scaphirhychus spp.) in the middle Mississippi River: Carbondale, Ill., Southern Illinois University, M.S. thesis, 79 p., [Also available at http://opensiuc.lib.siu.edu/theses/172/.]

Tracy-Smith, E., Galat, D.L., and Jacobson, R.B., 2012, Effects of flow dynamics on the aquatic-terrestrial transition zone (ATTZ) of Lower Missouri River sandbars with implications for selected biota: River Research and Applications, v. 28, no. 7, p. 793-813, [Also available at http://dx.doi.org/10.1002/rra.1492.]

Welker, T.L., Drobish, M.R., and Williams, G.A., 2017, Pallid sturgeon population assessment project, guiding document, volume 1.8: U.S. Army Corps of Engineers, 67 p. 
For more information about this publication, contact

Director, USGS Columbia Environmental Research Center 4200 New Haven Road

Columbia, M0 65201

(573) 875-5399

For additional information visit https://www.cerc.usgs.gov

Publishing support provided by the

Rolla Publishing Service Center 

